\title{
Television and the Public Sphere:
}

\section{Relationships of Power and Resistance in Contemporary New Zealand Television}

\author{
By \\ Frances Cook

\begin{abstract}
A Thesis Submitted to
Victoria University of Wellington

in Fulfilment of the Requirements for

The Master of Media Studies
\end{abstract}

School of English, Film, Theatre and Media Studies

Victoria University of Wellington

2011 


\begin{abstract}
This thesis considers New Zealand television's public sphere role, by analysing three television programmes in terms of how they enable the exercise of power or resistance. The programmes 7 Days, Campbell Live, and Shortland Street were used as case studies of typical public sphere spaces that are available to the New Zealand public. These programmes were analysed in terms of Foucault's concepts of power and resistance as active exercises that are present in all interrelations. The research found that the programmes were sites of both the exercising of power and the possibility of resistance, as they each worked to circulate competing discourses that subjects could take up to reinforce existing power structures or to resist the exercise of power upon them. Despite this conflicted nature, each programme was found to circulate these competing discourses in a manner that accommodated critical positions and discourses, as well as reinscribing normative power relations.
\end{abstract}




\section{Acknowledgements}

This project could not have been completed without the help and support of several people, all of which deserve great thanks. Tony Schirato for his insights, expertise, and willingness to hunt me down when I hid from an overwhelming workload. Ben Reed for his encouragement, patience with my late nights at the office, and unwavering faith in me. My parents and family for their support and willingness to listen. My friends, and especially the postgraduate community, for sticking with me while I descended into incoherency. 


\section{Contents}

Chapter 1: Introduction $\quad 4$

$\begin{array}{lr}\text { Chapter 2: Literature Review and methodology } & 8\end{array}$

Power 8

$\begin{array}{ll}\text { The Public Sphere } & 14\end{array}$

Medium and Methodology 17

$\begin{array}{lr}\text { Genre and Methodology } & 20\end{array}$

Chapter 3: Campbell Live Results

Current Events as Conventional Public Sphere 24

Soft News and the Requirement for Entertainment 28

The Expansion of the Conventional Public Sphere 31

Chapter 4: Shortland Street Results

Soap Opera as Feminine Public Sphere 35

Discourses of Hysteria 42

Overcoming Hysteria Through Gossip 46

Chapter 5: 7 Days Results $\quad 51$

Comedy as Subversive Public Sphere $\quad 51$

Commercialism and National Identity

The Inherent Ambiguity of Comedy 59

$\begin{array}{ll}\text { Chapter 6: Discussion } & 63\end{array}$

The Inclusive Public Sphere $\quad 63$

The Representative Public Sphere $\quad 68$

$\begin{array}{ll}\text { The Contested Public Sphere } & 72\end{array}$

The Role of the Nation 77

$\begin{array}{ll}\text { Chapter 7: Conclusion } & 84\end{array}$

$\begin{array}{lr}\text { Works Cited } & 89\end{array}$ 


\section{Chapter 1: Introduction}

This thesis will examine how New Zealand television functions as a public sphere. The public sphere is a space that allows citizens to come together to share information and critique those in positions of power (Schirato et al. 113; Briggs 4; Fraser 489). This is essential for the operation of democratic society, and for citizens and state to be able to communicate (Schirato et al. 113; Couldry et al. 4). The public sphere is not a singular unified space, but a term that describes a network of many sites of communication, which citizens can use to access and disseminate information and discussion (Schirato et al. 110; Simons 186; Dahlgren 412).

Three television programmes were chosen as case studies for this research, so as to reproduce the multiple nature of the public sphere. Campbell Live, Shortland Street and 7 Days represent a range of genres, comprised of current affairs, soap opera, and comedy; this allows for the examination of the possibilities of public sphere activity within each genre. Television is a potentially significant space of public sphere activity. The diversity of programmes and genres on television increases its ability to function as a critical public sphere, ensuring that a diversity of audiences and discourses are included (Fraser 499; Ong 55). Television was chosen as the example with which to examine the modern mediated public sphere because it is a highly accessible and appealing medium, present in the homes of most New Zealand citizens, and requiring only basic cultural literacy to understand (Couldry et al. 23; Slade 59; Zoonen 101). The wide range of citizens that are able to engage with the medium mean that its information, discourses and accounts, are an important contributor to the opinion formation and lived culture of citizens (Hall 367).

This critical public sphere that is provided by New Zealand television is necessarily imbricated in wider relations of power. Foucault defines power as an active exercise in which one group or individual makes another group or individual do something that they would not otherwise have done (Foucault "Sex, Power" 167; Foucault "Two Lectures" 28). Modern techniques of power achieve this through the widespread and continuous dissemination of normative identities, discourses and narratives (Foucault "Two Lectures" 41; Schirato and Webb 132; Smart 86). The exercise of power through norms is facilitated through the acts and mechanisms of interpellation; for instance, the media frequently addresses or calls upon citizens as either dutifully patriotic or as invested in democratic systems of critique (Brady 
and Schirato 37; Althusser 105). As the public sphere of New Zealand television authorises itself by claiming to enable viewers to access information and knowledge relevant to their role as informed citizens, it can be assessed in terms of how it challenges or reinscribes existing discursive regimes.

There are a number of issues or problems with regard to television taking on this public sphere function, including the one-way relationship of broadcaster to citizen, and the commercial logics that inform the way television represents debates and issues. While public sphere activity is meant to allow open discussion and information dissemination between citizens, most citizens are not able to contribute to or influence televisual accounts and representations (Perry 37; Hall 370). The dissemination of conservative or normative discourses are therefore both pervasive and accordingly, influential; and citizens are forced to rely upon the televised public sphere to ensure a critical space more or less in opposition to its own tendencies, practices and logics (Fraser 496; Hall 370). The commercial nature of television will also potentially limit its ability to produce critical positions and discourses, and is aggravated by the problem of the one-way relation between broadcaster and viewer. Television programmes must adhere to the commercial realities of television production, otherwise they are unlikely to be broadcast for long (Webb et al. 188; Murdock 176). These commercial influences often directly conflict with public sphere activity, creating a preference for simple discourses that are easy to consume, and sensationalism that increases audience numbers (Webb et al. 193; Schirato and Webb 174).

Chapter 2 outlines these concepts in greater detail, explaining the methodology and literature that informs this thesis, as well as their uses and limitations. A detailed explanation of Foucault's concepts of power, bio-power, and discipline is given, as well as an account of how these concepts impact upon the subject and alter public sphere communication. This explanation moves past simple notions of power as a static position held by certain individuals and institutions, and considers power as an active exercise that unavoidably produces instances of resistance. The evolution of public sphere theory is then explained, as well as the influence of mass media upon public sphere theory and processes. The chapter finishes with a brief overview of the relation between television genres and public sphere activity, and provides an introduction to the programmes used in this research.

Chapters 3, 4 and 5 analyse each of the programmes in terms of their public sphere activity. Chapter 3 looks at the relatively conventional public sphere role that is associated with current affairs television, and considers how Campbell Live fits in with and responds to those imperatives. Campbell Live interpellates the audience to actively participate in the public 
sphere by prompting them to email the show and then including these emails in the programme broadcast. This is then contrasted with the constraints of commercial influences that the programme accommodates, such as ratings which necessitate the inclusion of uncritical soft news stories that tend to reinscribe normative discourses and values.

Chapter 4 analyses Shortland Street's role as a gender inflected public sphere, which it achieves by using a narrative that prioritises what are generally considered to be women's issues, and by emphasising the personal and the affective. This allows Shortland Street to 'work through' social concerns, subjecting them to extensive discussion without offering a firm solution (Ellis 68, in Briggs 9). The programme discusses complex social issues and concerns within the setting of a familiar and understandable domestic setting, which gives Shortland Street the potential to non-normative identities so that they are accessible to the audience (Casey et al. 224; Bignell 172). These potential consequences are limited, however, by the hysteria that 'social issue' storylines are initially met with. Although the emotional tone of soaps allows for audience identification, it also serves to problematise that which it addresses (Hopkins 99; Hobson 142).

Chapter 5 discusses the generic aspects of comedic television, and considers how they enable 7 Days to carry out a public sphere function. Humour relies on variety of narrative techniques including surprise, violation of expectation and incongruity, and when these are brought to bear on normative and doxic assumptions, and on the discourses of power, they have the potential to undermine their authority. 7 Days uses this humour to deal with news events of the past week in an engaging and entertaining manner. The combination of a critical attitude with entertainment means that the programme is able to involve a large audience in public sphere dialogue (Zoonen 110; Murdock 178). However, the public sphere activity of 7 Days is limited, as is all comedy and humour to some extent, precisely because it often represents itself as something that is not to be taken seriously.

Chapter 6 brings together the trends and issues that have been identified in the previous three chapters. This chapter discusses how the inclusive nature and representative claims of each programme enables the fulfilment of main public sphere requirements, by interpellating a wide demographic of citizens to actively participate in public sphere consideration, reflection and discussion. This is then contrasted with limitations that the programmes faced, most notably commercial imperatives and particular genre restrictions that limited the articulation of critical positions and opinions. This discussion shows how contrasting influences impact upon each programme, leading to a conflicted and contested public sphere. The conflicted nature of the televised public sphere in New Zealand is then demonstrated by 
showing how each programme uses New Zealand national identity as an underlying metaidentity that was safe from criticism or challenge.

Chapter 7 presents the conclusions, explaining how the public spheres provided by New Zealand television are conflicted spaces that circulate discourses that are both reinscriptive and critical of power. This demonstrates Foucault's argument that power and resistance are endemic to communication rather than separate occurrences, both discourses existing only in relation to each other (Foucault "Critical Theory" 128; Foucault "Sex, Power" 167). The conclusion then shows the main ways that each programme works as conflicted sites of both power and resistance. 


\section{Chapter 2: Literature Review and Methodology}

\section{Power}

This thesis focuses on Foucault's conception that power is "neither given, nor exchanged, nor recovered, but rather exercised, and exists only in action" (Foucault "Two Lectures" 28). Power is exercised by making an individual do something that they would not otherwise have done (Foucault "Sex, Power" 167; Kelly 1). Foucault contends that power is always present, as are forces of resistance to it: while power can have constraining effects it can also operate as a productive force, producing both through its exercise and the exercise of resistance to it (Foucault "Sex, Power" 167; Gauntlett 131). Foucault suggests that if an individual has no choice or resistance this is obedience rather than an exercise of power (Foucault "Sex, Power" 167). However, the impossibility of a society without relations of power and the potential for power as a productive force does not mean that the specific power relations currently directing a society are either necessary or inescapable (Foucault "Subject and Power" 343; Kelly 1 ; Rose 147). While individuals cannot move outside power they do have many options within the power relationship, and the ability to alter it (Foucault "Sex, Power" 167; G. Palmer 3).

Indeed, power is not conceived as a single negative force held by a single sphere or group that dominates society in entirety (Foucault "Critical Theory" 128; Foucault "Sex, Power" 167). Rather, Foucault's work describes power relations as constantly in relation to one another, even if their struggle is not equal (Foucault "Critical Theory" 128; Foucault "Sex, Power" 167). Within these power relations citizens are not the mute objects of power but the vehicles of it, circulating within power networks both exercising power and having it exercised upon them (Foucault "Two Lectures" 36). This means that power is multiple and unable to be guaranteed, as resistance is inherent to the multiple networks and individuals that power seeks to operate through (Dahlgren 423). These power relations do not come into effect by laws or regulations, but through the creation of norms that appear natural and inevitable (Foucault "Two Lectures" 44). Nongovernmental social powers are particularly potent because they do not ask for, nor require, consent, and shape citizens subjectivities (Ransom 13). Power relations work to effect decision-making through multiple influences that are exercised through the deployment of varying methods and strategies, including that 
of discourses in the media, to make certain outcomes appear obvious and others ludicrous (Foucault "Critical Theory" 128; Foucault "On Power" 104).

Governance is therefore a system of shaping citizen's behaviour to achieve the objectives of specific power relations (G. Palmer 2). Although the name implies a government role, governance may be used by any entity or individual to effect action and expectations. While the exercise of power by the state is significant for this thesis many other power groups are included, as political power is neither the only, nor the most effective, form of power (Foucault "Intellectuals" 213; Ransom 14). Governments must maintain a position of power, rather than inherently possess it, and the same is true for each socially powerful group (Foucault History of Sexuality 93). These power relations can be identified both in large government institutions and in the working of the family - they are not bound to specific places or people, but rather act through a network of constantly shifting power positions (Foucault "Critical Theory" 129; Gauntlett 128). The governance which power achieves refers not only to the government of states, but to the control of all individuals, communities, and souls, by structuring the possibilities available to them (Foucault "Subject and Power" 341). Indeed, the forces used to achieve governance are increasingly exercised by factors other than the state itself (Nugent 214).

Because power relations are multiple, it is important for this study to choose a particular technique of power to focus upon. Contemporary power relations often work to reinforce Foucault's concept of bio-power. Bio-power emerged as a coherent political technique in the seventeenth century, and has become arguably the dominant means of effecting governance in modern times (Dreyfus and Rabinow 133; Foucault "Two Lectures" 41). It has two chief concerns, the first to collect scientific knowledge about the human species, and the second to manipulate the human body to become part of a productive human workforce (Dreyfus and Rabinow 134; Kelly 1). Bio-power uses exacting, active techniques of power generated by the human sciences to act upon and control the human body (Foucault "Two Lectures" 28; Foucault "Technologies" 224). These techniques are deployed with the goal of ensuring the continued dominance of the power position for its own sake (Dreyfus and Rabinow 137).

Modern power is first concerned with the collection of knowledge, as the process of discipline and bio-power is founded on the development of the human and social sciences (Foucault "On Power" 106; Dreyfus and Rabinow 134). These knowledges work to control subjects through constructing certain actions as "abnormality, madness, illness, and so on" (Foucault "Interview" 283). Knowledge is often seen as either neutral or oppositional to power, representing itself as a disinterested field that gathers pure information (Ransom 19; 
Nealon 95). While it may be recognised that knowledge can be used by power, this is viewed as power perverting knowledge (Ransom 19). While truth and knowledge are not framed as completely devoid of power, they claim to be in the service of a higher good than what power structures pursue (Dreyfus and Rabinow 129). The belief that power and knowledge are opposing forces is driven by a conception of power as a singular, negative force that constrains individuals, rather than the complex network of relations that this research constructs them as (Dreyfus and Rabinow 129; Foucault "On Power" 102).

Indeed, Foucault argues that knowledge is institutionally tied in to power relations, by the very fact of choosing what to study, how to study it, and how to interpret the results and apply them (Foucault Discipline 296; Bouchard 25; Foucault "On Power" 106). The social sciences frame human behaviour as a problem to be resolved, and the information generated provides those in positions of power with the necessary specific and measurable information to successfully discipline subjects (Ransom 22; Dreyfus and Rabinow 137; Foucault "On Power" 106). It ascertains where power is being successfully exercised, where it is weak, and what can be done to strengthen this exercise of power (Dreyfus and Rabinow 137). State intervention is often justified and expressed in terms of identified problems that need fixing, such as disease or work, that have been identified by these fields of research and knowledge (Dreyfus and Rabinow 140). The exercise of power through knowledge avoids opposition by concealing this relationship (Dreyfus and Rabinow 130; Foucault "Intellectuals" 43). When fields such as the social sciences speak they lay claim to truth, thereby concealing the power that operates through the knowledge that they generate (Dreyfus and Rabinow 130; Foucault "Technologies" 224). As such, the rational use of power does not pervert knowledge, but uses it to its fullest extent (Gordon xix). Knowledge thus moulds the world that it would purport to describe, and is linked to power not through corrupting influence, but by the very fact of its endeavours (Ransom 19; Foucault "Subject and Power" 326).

This approach to knowledge is informed by a scepticism of the possibility of the emancipated subject, a subject free from mismanaged power that can then achieve greater things (Ransom 22; Foucault "5 January" 29). From Foucault's point of view, knowledge cannot help free subjects to return to a higher state of living because power relations are endemic to all interaction, a state outside of power relations thereby being unattainable (Ransom 22; Foucault "Sex, Power" 167). However, it should be clarified that the dispersed and concealed nature of power relations does not mean that individuals are constructed by power that can neither be located or opposed, or that any sign of consent is simply a mask for this all-pervading power (Ransom 21). Power and knowledge are conceived of as inherently 
linked through a "knowledge-power" sign, but in a way that is constantly shifting and changing in emphasis (Ransom 21; Bouchard 24). Power cannot be reduced to knowledge, nor vice versa, but their strong relation was a focus point of Foucault's work (Foucault "Critical Theory" 133; Ransom 24). Indeed, knowledge is also very important for enabling citizens to partake in democratic forms resistive action (Dahlgren 425). It is in the shifts in the alliance between knowledge and power that resistive possibilities are located, and able to be exploited (Ransom 21).

The second concern of bio-power, of creating a productive, docile body, is achieved through the exercise of disciplinary power (Foucault "Two Lectures" 41; Dreyfus and Rabinow 134). Once fields of research such as psychology have produced research that defines norms of behaviour, subjects are then shaped and corrected to conform to norms that make them more useful to those in positions of power (Schirato and Webb 132; Smart 86). Disciplinary power utilises specific techniques to guide individuals to optimal performance in relation to the norms of the human sciences (Foucault Discipline 179; Ransom 17). Creating social norms is a subtle and often more effective means of exercising power than an overt display of power and coercion, which is made more vulnerable to resistance through its obvious nature (Brady and Schirato 33; Foucault "Two Lectures" 44). Rather than intimidating citizens, discipline places citizens into "an environment that evaluates, corrects, and encourages responses according to a norm" (Ransom 18). This aims to train the body to react without thinking, producing bodily habits that are productive and work to reinforce those in positions of power (Foucault Discipline 152; Schirato and Webb 132; Foucault "Governmentality" 141).

Discipline through normalisation and monitoring has two stages. Foucault explains the first stage with the metaphor of Jeremy Bentham's panopticon prison design, which is devised so that prisoners can be observed at any time, but will never be aware of when the observation is taking place (Schirato and Webb 133; Sheridan 152). This metaphor for societal surveillance describes how disciplinary power renders its subjects visible, while obscuring itself (Smart 87; McHoul and Grace 24). This leads to the second stage of the exercise of discipline, in which subjects start to compare themselves with regard to scientifically legitimated norms, due to an awareness that others could be monitoring them (Foucault "On Power" 105; Schirato and Webb 133). The dissemination of norms and panoptic methods of surveillance invites the subject into a cycle of continuous monitoring and evaluating of the behaviour of themselves and others (Schirato and Webb 147; Foucault "Two Lectures" 44). Self-surveillance is achieved through the immersion in norms and 
discourses of various cultural fields, so that the subject takes on those fields and monitors themselves in accordance with them (Schirato et al. 52; Foucault "Two Lectures" 44). This system of self-surveillance is an economical form of governance and population control, as subjects become implicated in monitoring themselves and others, rather than power representatives needing to be constantly present (Schirato et al. 52; Foucault "Governmentality" 141; Escobar 251).

This process of setting norms that seek to mould citizen's subjectivity is particularly problematic because, rather than implementing illegitimate, legitimate, or consent driven methods of power, the constructed norms appear natural and outside the exercise of power (Foucault "Two Lectures" 44; Ransom 19). This makes discipline an exercising of power that is difficult to analyse or oppose, as it is only once individuals have already been moulded that they are capable of giving informed consent to the process (Ransom 15; Escobar 251). However, once the subject has been moulded they are enmeshed in the power relation, which renders the issue of consent moot (Ransom 13).

Technological developments are a key part of this process, as they have made it easier to not only produce exact measurements of 'normality', but also to disseminate the results of these measurements (Schirato et al. 53). The norms generated by knowledge are often picked up and disseminated by news media and popular culture, thereby providing subjects with the norms of evaluation and surveillance (Schirato and Webb 140). Most subjects want to be seen as normal and desirable, and thus are receptive to the dissemination of normalising templates through the media (Schirato and Webb 187). Popular culture can thus become a site that offers templates of normal and desirable subjects; this produces a cultural norm of what is normal and desirable for individuals to check their habitus against (Schirato and Webb 146). Mass media does, however, provides the widest range of these templates and is one of the most pervasive platforms for their dissemination, and thus has great influence (Schirato and Webb 187).

The dissemination of norms and exercise of disciplinary power is circulated through mediated communication by means of interpellation. Interpellation produces subjects and subjectivity through the use of discourses and modes of address to hail subjects, which trigger self-recognition in the subject, and therefore recruitment (Schirato et al. 53; Althusser 105). This works by an authority addressing an individual as a specific subject to which a subject responds, and this moment of subject's response authorises and validates the subjectivity that they were addressed through, thereby producing the individual as a subject (Schirato et al. 54; Althusser 105). In responding to the recognisable subject category that they were 
interpellated by the individual is produced as known, and thus is able enter into particular cultural fields (Brady and Schirato 37). The known subject categories which interpellation calls upon are at once both abstract and a material processes. The subject categories of fat, beautiful, intelligent, are not things but concepts, yet the application of these categories to a subject produces the perception of and connotations attached to the material body (Schirato et al. 55; Smart 75). This allows a subject to be recognisable and intelligible to others, and further, to be interpellated or called upon to take up certain subject positions with little explanation of what these positions entail (Brady and Schirato 2).

Power relations thus construct the subject, identifying them by the power positions that they have access to or are manipulated by (Foucault "Two Lectures" 36; Foucault "Subject and Power" 326). By responding, then acting in a manner congruent with the subjectivity they were addressed through, the individual submits to becoming a compliant subject (Schirato et al. 54; Brady and Schirato 31). In simple terms, "by acting as if we believe, we end up believing what we act" (Schirato et al. 54). The subject is complicit in this process, by recognising themselves in the interpellation and constructing themselves in response (Foucault "Subject and Power" 327). 'Subject' is not a term that is interchangeable with 'individual', but rather a stance an individual takes in a pre-existing category that they fulfil by submitting to the power relations involved in that particular subject position (Brady and Schirato 36). Subjectivity is driven by the authorised discourses and disciplines of the cultural field which the subject is currently in contact with (Schirato et al. 55; McHoul and Grace 22). Identity formation thus works through a particular grid of intelligibility, systems of already existing known categories that subjects can choose to take up or reject (Brady and Schirato 2; Althusser 105).

By disposing subjects to act in a manner conducive with the cultural field, interpellation encourages the subject to accept and abide by a particular set of social norms, and thereby be disciplined to becoming useful to that field (Brady and Schirato 13; Smart 80). Norms are then incorporated and displayed through the subject's bodily hexis, which entails the body's "movements, deportment, production of points of focus or emphasis" (Brady and Schirato 8). It is not just the body which contemporary power seeks to dominate, but its gestures, habits, and capacities; and the material reality of the body is inextricably linked to its evaluation in terms of the concepts of a normal and desirable body (Schirato et al. 55; Smart 85). Each cultural field "ascribes cultural capital to certain types of bodies and denies it to others" (Brady and Schirato 8). The displaying of these norms make bodies recognisable, and further 
brings subjects into the grid of intelligibility and recognisability (Brady and Schirato 12; Smart 80).

The understanding of power used for this analysis is therefore based upon Foucault's concept of power as relational; knowledge as implicated in the exercise of bio-power and discipline; and interpellation as a significant method of exercising techniques of power. These concepts of power relations, bio-power, and discipline inform the critique of the public sphere that this thesis is based upon.

\section{The Public Sphere}

While contemporary methods of power camouflage themselves through the creation of norms, they can be identified by their accompanying resistance which is often expressed more overtly (Foucault "Subject and Power" 329). An obvious site for the expression of opposition to processes of power and normalisation is the public sphere, defined as "the space for the exchange of ideas, of common debate and opinion formation which is either sustained or, in some accounts, attenuated by television and other mass media" (Briggs 4). The public sphere is conceived of as a space in which all citizens can contribute to public life and discussion through educated, rational debate, without restriction or oppression from those in positions of power (Briggs 5). A culturally designated space for informed discussion, without interference from market or government forces, is of great importance to the resolution of a wide range of challenges that impact upon the functioning of a democratic society (Silverstone 65; Couldry et al. 5).

This concept is central to contemporary society, as in order for democratic systems of power to work there needs to be systems for distribution of information and space for the subsequent discussion of this information (Schirato et al. 111; Fraser 489). The expression of public opinion in the public sphere theoretically acts as a check and balance to those in positions of power (Schirato et al. 119). Power representative cannot ignore the critique of the public sphere, as the expression of public opinion and debate is a recognised way of formulating and making known this will of the people, and a core principal of democracy is that the will of the people is what legitimises political activity (Schirato et al. 118; Couldry et al. 4). The use of the term 'public' rather than 'political' is deliberate and significant. While political issues are often a significant focus of the public sphere, the use of the term public avoids a narrow conception of the issues that are deserving of communal interrogation (Couldry et al. 5). 
Jurgen Habermas is perhaps the most influential contemporary theorist of the public sphere. He argues that the public sphere originated in eighteenth-century Britain, as a consequence of the emergence of the bourgeoisie, a class that had the time and resources available to engage in civil society (Silverstone 65). The bourgeoisie met in coffee shops to partake in rational, analytical discussion and debate over the affairs of government and business (Silverstone 65; Slade 61; Simons 176). The rise of the printing press was central to these discussions, as dissemination of information by print news provided politically motivated individuals with information about politically relevant events, thus aiding the construction of political opinions (Dahlgren 411; Silverstone 65; Simons 176). While Habermas's theorising of the public sphere has been refined by other theorists, it has a number of strengths that are still highly relevant. The first is Habermas's identification of the need for the public sphere to be separate from economic and State influences (Silverstone 67; Dahlgren 411). He also noted the importance of an independent media to provide unimpeded access to information from diverse perspectives (Silverstone 67; Dahlgren 411). Thus a familiarity with Habermas's work is an important starting point for any discussion of the public sphere.

However, Habermas's theory neglects the point that the public sphere has never been a utopia of public discussion and critique. His construction of the public sphere operates under the assumption that every individual could access all information and debates; and further, that the institutions which provided public information did so without any other agendas (Silverstone 67). Yet the bourgeoisie coffee shops were not equally open to all members of society, but were an exclusively male domain that was often further restricted to members of the upper classes (Silverstone 67; Schirato et al. 113; Fraser 491). Habermas also argued that the public sphere should conform to an 'ideal speech situation', meaning that logical, reasoned debate should be prioritised over emotional communication or narrative (Briggs 6; Fraser 491). This expectation of the public sphere is both narrow and exclusionary (Briggs 6; Simons 179). While sombre, rational speech is the traditional method of public sphere discussion, it is by no means the only method. Empathy is fundamental to human processes of conception, and emotional responses such as shock and identification can help audiences comprehend why individuals took the actions they did (Briggs 7; Simons 179).

As such, Habermas's concept of the public sphere forms the basis from which public sphere theory has evolved to a more populist notion that attempts to include all citizens, rather than only the educated classes of the bourgeois (Simons 172). The concept of the public sphere that is now accepted by theorists has four key aspects. Firstly, it is an area of 
social life where individuals can come together to behave as a public body, and express and form opinions (Schirato et al. 113; Briggs 4). Secondly, it needs to provide a network for transmitting these opinions and their discussion to other citizens (Schirato et al. 113; Fraser 489). Thirdly, the public sphere should be a space where political and public information is readily available, so as to enable informed democratic practice (Schirato et al. 113). The fourth and final aspect is that the public sphere should function as a mediator between the state and the society it governs (Schirato et al. 113; Couldry et al. 4).

The role of the public sphere is important because it functions both to educate and inform the public about important socio-political issues, and as a site of criticism and critique that helps to ensure that those in positions of wealth and influence do not abuse their power (Briggs 5; Corner and Pels 3). Without a space for the dissemination of information and discussion, democracy cannot function (Schirato et al. 115; Couldry et al. 4). The public sphere must therefore attempt to include and educate all citizens, and facilitate discussion and (Briggs 5; Simons 172). Crucial to this public sphere discussion is the notion of critical speech, which requires speaking of and demonstrating the truth in order to bring about change (Gordon xii; Foucault "27 January" 158; Foucault "12 January" 54). In doing so, socio-cultural concepts and practices can be brought into crisis, providing the opportunity to rethink and negotiate the categories that power is enacted through, and problematise the taken for granted activities that result (Foucault "3 March" 366; Danaher n. pag.; Foucault "10 February" 242).

However, the public sphere is subject to certain pressures and conditions of operation. As society is becoming individualised and fragmented the idea of social and cultural responsibility could be argued to be an outdated ideal, one that is difficult and possibly futile to uphold under contemporary pressures (G. Turner The Demotic Turn 2). Indeed, the public sphere itself is not even one entity that can be held to account, but is comprised of several sub-spheres, outlets of information and opinion that are influenced and shaped by the lifestyle, views, and demography of their target audience (Schirato et al. 110; Simons 186; Dahlgren 412). The public sphere can thus be visualised as a "network of spaces and activities" that provide the distribution and transmission of information and events that are needed for citizens to participate in political processes (Schirato et al. 110). While other spaces for interaction, including direct face-to-face interaction, are still used and important, electronic media is the most prevalent and salient form of public sphere for contemporary times (Schirato et al. 133). Modern electronic media provide a means for the transmission, 
discussion and interpretation of information and opinions, so that they can be transformed into understanding and engagement (Schirato et al. 112).

The prevalence of mediated public sphere activity is central to the discussion of the increasingly commercial form of the public sphere. Habermas argued that mass media lead to a 're-feudalisation' of the public sphere by removing face-to-face conversations, commercial interests then further limiting the possibilities for discussion and critique (Goode 20, in Briggs 5; Couldry et al. 126). However, Habermas's claims were based on his idealised concept of the bourgeois public sphere, and a greater understanding of print media than electronic, thus completely ignoring the increased reach and plurality of information enabled by electronic communication which offers greater possibilities for education and resistance among audience members (Silverstone 67; Schirato et al. 113; Corner and Pels 3). Despite the issues brought about by the increased prevalence and commercialisation of the mediated public sphere, it still contributes to a shared culture between citizens, an important public sphere function (Scannell 162, in Briggs 5). Electronic media has increased both the speed of dissemination, and the potential reach of cultural meanings and ideas (Schirato and Webb 172; Silverstone 67).

While arguments of a 'refeudalisation' of the public sphere appear untenable, there certainly are a number of issues with the media functioning as the main public sphere. The media is not a disinterested facilitator of communication; rather, it is part of the wider cultural fields of politics and economics, to name but two (Schirato et al. 120). Despite the appearance of many outlets of mediated information, media ownership is concentrated into surprisingly few hands, which makes 'information management' easier, and a plurality of viewpoints far more difficult (Schirato et al. 120). Even the technological nature of electronic media means that access to the mediated public sphere can be limited by unequal access, due to economical or geographical reasons (Schirato et al. 121).

\section{Medium and Methodology}

Television was chosen for this study because it is a largely unrestricted medium, able to be received at any one time by as many viewers as want to watch (Murdock 175; Bell 21). In a relatively affluent nation such as New Zealand there is a television set in practically every household, and it provides a daily space of lived culture that bases debate in the experience of ordinary life (Slade 59; Couldry et al. 23). This accessibility means that it is not only a space for citizens to come together, but also provides a voice that expresses this debate and the values that it is based upon to those in positions of power (Hall 367). Programmes were 
chosen from free-to-air channels, as free-to-air broadcasting is removed from the price system thereby allowing any citizen with a television is able to engage with the medium (Murdock 175).

Television is not only a widely available sphere, but a popular one with high viewing figures, as it produces programmes in a manner that aims to hold the viewer by being both entertaining and informative (Bignell 160; Corner and Pels 2). Television texts are certainly $a$ dominant means of working through social and political issues, and it is arguably the dominant means for contemporary times (Zoonen 100; Gauntlett 2). Audience members need to only possess basic cultural literacy to understand its images, which work in tandem with information and discussion to aid understanding and evaluation of events (Bell 21; Zoonen 101). Television thus the potential to provide the information upon which citizens will base decisions, giving viewers material for casual conversation and opinion formation (Slade 59; Dahlgren 411). Despite these potentialities, television as mediator of the public sphere has both inherent capabilities and limitations that are due its specific conditions of production.

A fundamental limitation of television's role as a facilitator of the public sphere is its commercial nature, which requires that it operate under the constraints of both time and effect (Webb et al. 188; Murdock 176). Television is under greater time constraints than print or new media, which leads the medium to decontextualise issues and discuss them in terms of simple oppositional binaries, such as right and wrong, or citizens versus foreigners (Webb et al. 188). The simplification of issues is partly a consequence of the need to attract mass audiences and advertising revenue (Murdock 176). Television is therefore committed to the market imperative as well as the facilitation of communication and critique, and these commercial imperatives forces genres such as the news to abandon their core values in favour of profit and time efficient sensationalism (Webb et al. 193; Schirato and Webb 174). These issues of simplification and commercialism are difficult for citizens to contest, as broadcast communication is often one-way, with viewers having little chance to contribute to the medium rather than simply consume it (Murdock 178).

While television has a tendency to reproduce dominant regimes because of this simplification and commercialism, there are exceptions to this rule (Schirato and Webb 188). Cultural products must establish their own value, and in order to be viewed as a legitimate public sphere there is a requirement to gesture towards including all of the public, even if these gestures are infrequent (Bourdieu "Field of Power" 90; Schirato and Webb 190). Without these gestures, public sphere sites lose their legitimacy, and thus much of their power (Schirato and Webb 190). Members of cultural fields such as journalism retain a 
commitment to their fields values because of the durability of habitus, which provides one of the strongest resistances to market domination (Webb et al. 195).

Television addresses modern society at the micro level of control and ideology, framing discussion and critique in terms of the routines of daily life (Silverstone 52). As a domestic technology, television is often given a low, background level of attention, but this attention is for a long duration, with the contemporary audience integrating television into their domestic routine (Ellis 68, in Briggs 9; Bignell 172). Television's privileged and omnipresent existence within the private, domestic space gives it greater capacity to function as a mechanism for citizens to work through concerns and events (Ellis 68, in Briggs 9). Television uses this domestic setting to constantly work through complex issues and problems, providing discourses and resolutions that can be taken up by audiences and deployed in their daily lives (Briggs 11). The public spheres of television are particularly dominated by Ellis's concept of 'working though', in which he argues that television offers a daily opportunity for citizens to process and work through topics, contest themes, and examine explanations of the world, without offering explicit solutions (Ellis, in Briggs 7; Dahlgren 420). The concept of the 'worked through' public sphere is particularly relevant for television because of its centrality to domestic space, as a medium which is used in a distracted and discontinuous manner; examples of this include debates regarding identity, and legitimate or otherwise cultural norms (Briggs 9; G. Turner The Demotic Turn 3).

While television programmes clearly neither aim to, nor are capable of, presenting an accurate representation of society as a whole, the reason that its stories resonate with viewers is because they connect with concerns relevant to contemporary society (Bignell 161). Thinking of television's public sphere role in terms of 'working through' widens the concept of public sphere (Briggs 8). As a domestic technology, television domesticates public and political life, while simultaneously bringing the domestic into the public realm (Silverstone 68). This is because television deals with public sphere issues at the domestic level, working through information and ideas in an everyday manner, using stories and gossip to make the ideas fit into daily routine (Silverstone 68). As such, television's fictional stories often present communities which then work through contemporary concerns (Bignell 161). The process leading to political decisions is extensive and the public working through of issues on television significantly aids the process (Dahlgren 420).

As a domestic, intimate technology, television functions not only to facilitate the public sphere, but to also contribute to the meanings and narratives that an individual can draw on to make sense of the world (Briggs 9). Rather than viewing television as a single space of power 
or resistance, it is conceived as a field of power relations, a "mode of articulation between social groups and actors" (Mattelart and Mattelart 78). Television is a contributing influence to individual meaning- and decision-making, along with belief systems, the workplace, and family (Briggs 9). While the discourses that television promotes are part of a larger dialogue between competing producers of meaning, the moving images of television give a sense of immediacy and authority to these multiple narratives, and particularly for fact based or news programmes, authorises the claims and norms that a programme prioritises (Briggs 10; Thussu 19). Television punctuates the meaning making process in the brief window of audience attention it is afforded, after which the meanings that individuals take from it become part of a system of competing meanings and values that they subscribe to (Briggs 10).

\section{Genre and Methodology}

'The media' is a similar misnomer to 'the public sphere' - both use a singular term to describe multiple, contested spaces of debate (Couldry et al. 24). While there are influences that shape television as a public sphere, there are also specific influences that shape the different television genres. Diverse citizens and rhetorics require diverse spaces for their representation, and the different genres enable this by structurally prioritising different discourses and audiences (Fraser 499; Ong 55). This study therefore used three programmes from three different genres to examine how distinct public spheres were constructed, focusing upon a textual analysis of these three programmes in terms of both their public sphere role, and as sites of power discourses. Although the audience is conceived of as active and capable of forming resistance, it is still acknowledged that they are not completely autonomous however active their response, it is still in response to an initial media text (Mattelart and Mattelart 81; Bignell 176). Hence textual analysis is useful to examine how these power relations are initially conceived and transmitted.

The most obvious and explicit public sphere space in television is news and current affairs, as the journalistic field is predicated upon principles of "truth, accuracy, freedom of speech, the public's right to know, unbiased reporting and independence" (Webb et al. 183). Journalism is the field most similar to the original bourgeois public sphere which made the state accountable to the people through publicity and public discussion, as the news sphere has closely aligned values of emotionless fact and politically relevant real events (Fraser 490; Slade 37). However, television news is particularly bound by the aforementioned time constraints, as it has a great deal of stories to cover in a limited amount of time, and must do so in a manner that still evokes interest (Webb et al. 189; Bourdieu On Television 1). It 
therefore becomes routine for news stories to be discussed without reference to context or previous events, instead explained primarily through visuals and terms of human effect which use recognisable oppositional binaries such as citizens and foreigners (Schirato and Webb 179; Webb et al. 189). These time constraints obstruct an in-depth understanding of events and instead simply work to effect an individual's emotions (Bourdieu On Television 1; Webb et al. 189).

These constraints influenced both the choice and analysis of Campbell Live. Campbell Live is a current events programme that airs on New Zealand television immediately after the $6 \mathrm{pm}$ news for half an hour each weeknight. While news communicates information, current events focus upon helping an audience understand the information, working against the constraints of time and affect that news operates under and interpellating viewers as active and invested parties (Holland xiii). True to its genre, Campbell Live's time is devoted to an in-depth discussion of the most salient three or four news stories of the day. This understanding of politically relevant events is undertaken in a space that prioritises detached critical thinking, offering viewers a worked through interpretation of events, including speculation as to meanings or causes (Danaher n. pag.; Ellis 58, in Briggs 8). Current events programmes are thus able to involve citizens in public sphere discussion that takes greater account of an issue's context (Anderson et al. 3; Holland xv).

A less typical public sphere is soap opera, for which Shortland Street is used as a case study. Soap opera was initially created as a vehicle for attracting female listeners to radio timeslots sponsored by detergent companies, and thus prioritised a structure that permitted housewives to listen to on the radio without being distracted from carrying out their domestic chores (McCarthy "Studying" 47; Bowles 188; Casey et al. 222; Silverstone 73). Longrunning family dramas proved most successful in attracting and maintaining this audience, and the genre retains this history by remaining a primarily female genre that constantly works through domestic, family, neighbourhood and work concerns (Slade 70; Silverstone 73). Soap has since become a mainstay of television broadcast schedules worldwide, as they have low production costs, and tend to attract loyal audiences for decades at a time (Bowles 188; Casey et al. 223; Seiter and Wilson 136; Geraghty "Study" 310). Shortland Street is not only New Zealand's only locally produced soap opera, but is broadcast on TV2 at 7pm on weeknights, this regular spot during prime time on a main channel showing the priority that the programme is given. Shortland Street combines high ratings with frequent inclusion of controversial storylines and characters, which made the programme an obvious choice for this study (Lealand "Quality Television" 133). 
Soap opera is a genre that has taken on the specific role of working through domestic issues, producing incessant crises and taking on issues of current societal importance, but in a careful manner so as to not alienate any of their audience (Schirato and Webb 188; Silverstone 72). Soap is one of the prime examples of television's worked through public sphere, due to its use of multiple narratives, representation of issues of current social concern, and position as a talking point between audience members (Briggs 8). Fiction is used by soap to narrativise current social or ethical issues of concern which provide the public sphere with a platform for discussion of personal themes in a public manner (Briggs 8; Slade 69; Couldry et al. 8). Soap's working through is situated in the community, as location is the key binder for soap characters, with characters also forming bonds and alliances due to familial relations or age, which are then used to progress storylines (Bignell 161). Soaps appeal due to the 'pleasure of familiarity' which these community based narratives produce, and therefore are vulnerable to reproducing dominant ideologies because they do not want to lose their audience (Schirato and Webb 188).

The last genre included in this study is comedy, for which the programme 7 Days is the object of analysis. 7 Days is a half-hour weekly programme that uses the news of the past week as a base for comedy, therefore prioritising humour that focuses upon figures and representatives of power. The programme is hosted by Jeremy Corbett, and features two teams of three comedians who compete to be the wittiest, as chosen by Corbett. Only Corbett and the two team captains return each week, with the other four comedians made up of a revolving cast of semi-regular local comedians, and less frequent international comedians. Comedy has inherent subversive potential, as it works through subverting viewer expectations in the moment of the punch line, potentially exposing the constructed nature of norms of behaviour (Neale and Krutnik 88). This subversive nature combines with the use of news material for a strong potential for aggressive critique. This potential is furthered by 7 Days' use of satire, a mode of comedy which uses humour to aggressively reveal the constructed nature and contradictions in norms, essential to exposing contemporary power relations (Neale and Krutnik 19).

Comedy invites a particular relationship with its audience that makes this subversion and critique more likely to succeed. Comedy focuses on the everyday and ordinary moments of daily life, thereby inviting a similar pleasure of familiarity to soap (Neale and Krutnik 11). By framing critique in the everyday subversion has the potential to be effective, as audience investment in comedy is heightened and issues of power and ideology are ensure relevancy to the audience (Neale and Krutnik 11; Silverstone 52). Truth and knowledge claims are used to 
invite viewers to monitor and transform themselves, but this relationship combined with the absurdity of comedy and the comedian to create the potential to negate this (Smart 108). 


\section{Chapter 3: Campbell Live Results}

\section{Current Events as Conventional Public Sphere}

Campbell Live is a current affairs programme that broadcasts weeknights on TV3, with John Campbell as the main host. The programme represents the most explicit and obvious site of public sphere activity in this study, as current affairs programmes "appeal to understanding, reason, participation and universality" (Holland xv). The field of journalism is strongly informed by the ideal of a 'fourth estate' function, which leads news programmes to prioritise the rational critique that the public sphere demands. It reports upon politically relevant real events, and values verification of fact, providing both information and the debate of this information to viewers (Slade 37).

While news and current affairs programmes are strongly linked, there is an important aspect of difference in their aims, as typical news programmes aim to inform populations what it is that has happened while current affairs programmes aim to help viewers gain a full understanding of the most important of these events (Holland xiii). Current events programmes work to rectify the effects of the barrage of information provided by television news, which often overwhelms audience members so that they do not remember all of the stories or lack understanding of key terms and context (Couldry et al. 32). At the core of this process of understanding rather than telling is an interpellation of audience members as active, critical subjects, rather than passive viewers (Holland xv). Although television news is greatly constrained in terms of the time they can give to the multiple stories they need to cover, current affairs programmes are able to include more background and context into a discussion because of their increased focus on fewer stories (Anderson et al. 3). These differences can be seen even in the placing of the shows in the programme schedule. TV3 airs 3 News at 6pm, followed immediately Campbell Live at 7pm which discusses the most important and contentious of those stories.

The current events genre therefore provides a base that is highly conducive to a public sphere role, and these aspects are amplified by host John Campbell. His interaction with news stories and public figures is highly critical, personifying the news and public sphere values of rational critique. This was highlighted during Campbell Live's investigation of the possibility of mining on conservation land. Ongoing discussion of the issue was commenced with an interview between John Campbell and Gerry Brownlee, Minister for Energy and Resources 
(“22 March" Campbell Live). In beginning a week-long discussion of mining in this manner, Campbell Live clearly delineated the Minister both as someone who warranted inquiry and as accountable for the issue. This effect was increased by John Campbell conducting the interview in a critical manner. When Brownlee stated how many hectares of public conservation land was being investigated for mining, John Campbell argued that the number wasn't final and could "creep up” (“22 March” Campbell Live 01:49). John Campbell then repeatedly asked Brownlee to acknowledge that the number he stated was an opening number and could grow, and when this was unsuccessful, listed the areas currently under discussion and asked Brownlee to justify their inclusion ("22 March" Campbell Live 02:01-04:10).

These techniques utilised both an aggressively questioning approach and demonstrated John Campbell's knowledge of the issue, thereby framing himself as a representative 'of the people' that demands answers. In rebuffing Brownlee's presentation of facts through aggressive questioning he resisted the authority of a power representative's claim to truth (Foucault "Sex, Power" 167). This resistance was taken further by John Campbell actively changing the situation that power operated through, his confrontational questioning setting up Brownlee as a representative of countervalues, and as part of 'them' (Foucault "Sex, Power" 168; Campbell 316). In contrast, John Campbell becomes a mediator between the tensions of 'us and them', holding Brownlee accountable and demonstrating his reliability as a representative for the people by exposing Brownlee's countervalues (Campbell 317; Fraser 490).

That this aggressively questioning approach is undertaken on behalf of 'the people' is reinforced in John Campbell's performance throughout the show, welcoming viewers to the programme and using conversational language, thereby giving the illusion of direct address and inclusion of the audience (Casey et al. 86). These linguistic and bodily performances work together to authorise John Campbell's questioning of power figures, legitimating critique and the social value that it represents (Bourdieu "Field of Power" 487). This disposes the audience to accept John Campbell's critique of events and is therefore a more active method of resistance because of the possibility for change that it creates (Campbell 317; Foucault "Sex, Power" 168). By framing himself as both a representative of the public and a critical thinker, John Campbell invites the audience to engage with the public sphere in a similarly critical manner. Regular viewers of the show could conceivably incorporate these values into their own habitus and use a similarly critical mindset in other areas.

This example of the critical thought that Campbell Live endeavours to provide is crucial for democracy to function and as a negation of the processes of discipline. Media, and 
particularly news media, are at the centre of democratic systems, with television news working as the primary source mediated information that makes it possible to be aware of any of the multitude of political events occurring daily (Allaun 15; Couldry et al. 32). At an ideological level, the modern media is committed to informing citizens, and in this process of informing Campbell Live is able to bring attention to techniques of discipline and problematise outcomes that power discourses endeavour to frame as natural and inevitable (Allaun 12; Corner and Pels 3; Foucault "On Power" 104). Detached thinking promotes questioning and opens up the possibility for thinking otherwise, creating possibility for the subject to take more control within the system of disciplinary bio-power (Danaher n. pag.). The rules of a cultural field become part of the subjects habitus through the subjects participation in that field (Danaher n. pag.). By the subject engaging with a cultural field that critiques power and systems of doctrine subjects have the opportunity to incorporate a detached, critical disposition into their habitus, creating the possibility for resistance against the subtle norms of discipline (Danaher n. pag).

The detached mode of thinking used by reporters such as John Campbell gains its mannerisms and legitimacy from its association with the fields of knowledge (Campbell 312). As previously mentioned, knowledge is a form of power that gains its legitimacy from appearing outside of power, and the perception that knowledge frees subjects from the constraints of power relations (Foucault "On Power" 106; Gordon xii). Campbell Live is able to utilise these characteristics to invest its critique of sites of power with the authority of knowledge and truth (Foucault "Two Lectures" 23). Critical thought is presumed to react to something other than itself, rather than speaking from a position of invested interest which uses messy personal opinions (Danaher n. pag.; Hartley 109). John Campbell's role in Campbell Live reinforce these ideals of critical thought, his position as studio anchor, used to introduce stories or conduct the most important, aggressive interviews, personifying these values through his detached yet engaged presence. Even when John Campbell interviews the spokesperson for the Lemon Detox Diet the interview is conducted after a segment, prepared by another journalist, which gives the audience information about the controversy that the company behind the diet is involved in ("16 March" Campbell Live). This technique of John Campbell conducting an interview in the wake of outside information is repeated throughout the show, the mining interview with Gerry Brownlee commencing with an unfavourable quote from a Forest and Bird spokesperson ("22 March" Campbell Live 00:25).

The field of journalism takes up this mode of critical thought and speech precisely because it forms a type of action (Danaher n. pag.; Sheridan 128). As mentioned, the act of critical 
thought and speech forms a barrier against the processes of discipline and bio-power, and this barrier in itself is an act of resistance (Foucault "Two Lectures" 31; Danaher n. pag.). The use of these techniques allow John Campbell to remain removed from criticisms of institutionalism, authenticating his truth claims so that he can take on the role of 'people's representative'. While political reporters, and even regular news programming, often face accusations of institutionalism, current affairs show hosts like John Campbell have the capacity to appear autonomous, and therefore to enact critique in a manner that the audience is more likely to be receptive to (Campbell 325). In ostensibly performing critique of institutions and individuals in positions of power, Campbell Live actually works to critique the techniques of power that they exercise (Foucault "Subject and Power" 331; Foucault "Space, Power" 166). Journalism therefore actively performs itself as a site of resistance to dominance through speech, particularly requiring a subject to perform their speech as frank thoughts, and to demonstrate that "there is a corollary between one's words and one's beliefs and actions", rather than attempt to influence through persuasive patterns of speech (Danaher n. pag.). Campbell Live constructs itself as a sympathetic platform for citizens who wish to know what is happening around them, and think critically and responsibly.

The most explicit performance of this occurred when John Campbell interviewed the two men who had vandalised the Waihope spy base, the interview taking place outside the court room immediately after the men had been found not guilty by jury ("17 March" Campbell Live). John Campbell clearly felt that the interviewed men were a shining example of "truth telling', as he emphasised that the two men had never denied their actions, but instead based their legal defence on the right to destroy property in the defence of other citizens (" 17 March" Campbell Live 02:17). John Campbell then asked the men to explain their actions, and in contrast to his interview with authority figure Gerry Brownlee, always allowed them to finish what they were saying, addressed them in a friendly tone, and nodded sympathetically while they were speaking ("17 March" Campbell Live 03:05). In doing so, Campbell Live provided a platform for the men to explain their actions in a full and candid manner. As the two citizens were brought before the courts for their actions, it was clearly demonstrated that not only did the men fulfil the criteria of backing their words with action, but that they were willing to put themselves at risk and expose themselves to those with greater power, in the pursuit of truth. Campbell Live rewarded these actions by facilitating access to the public sphere.

Contemporary critical thinking is thus a mode of thought that prioritises both a fearless commitment to the truth and a detached manner of engagement. Audience members are 
interpellated to actively participate in this sphere by being prompted throughout the programme to email their thoughts and feedback on stories in the 'Your Opinion' section. Campbell Live includes at least two sections of 'Your Opinion' in each broadcast, in which viewer emails are displayed on screen as John Campbell reads them aloud. This integration of viewer feedback through email allows Campbell Live to move past information dissemination to include public sphere debate and critique from 'ordinary citizens' (Anderson et al. xix). Mass news systems are not conducive to active participation by members of the public, which leaves journalism in danger of becoming a mere conduit of information, rather than the resistance as practice that is necessary to oppose the exercise of power (Anderson et al. 9; Foucault "Space, Power" 165). The integration of interactive features such as viewer feedback on the internet that is integrated into the broadcast show creates a more open, inclusive public sphere, in which journalists are more capable of fulfilling their promise to speak with and for the people (Anderson et al. 9). The 'Your Opinion' section further normalises dissent and opposition, which interrupts the processes of normalisation, and has the potential to encourage audience members toward critical thought processes. Campbell Live rewards viewers who submit email examples of critical though by including them in the programme but not subjecting them to critique or discussion within the programme, providing viewers the same sympathetic platform for truth telling as the men involved in the Waihope spy base example.

\section{Soft News and the Requirement for Entertainment}

While Campbell Live is thus a valuable space of public sphere activity, it has significant limitations. The commercial imperative to deliver audience members to advertisers conflicts with the public sphere concern of active critique (Holland xvi). Television journalism is in a predominantly commercial, competitive environment, which means that journalistic values are often given a lower priority than economical imperatives; news is a business, and other values must fit around this core imperative (Webb et al. 184). News and current events programming is faced with commercial pressures because of their important role in which channel an audience member will watch for the entire evening (Slade 38). As part of ensuring that the programme is a ratings success, Campbell Live includes many soft news pieces, a demonstration of how the enforcement of commercial objectives are difficult to reconcile with public sphere values of detached, critical thinking (Holland xvii).

While these soft news pieces are entertaining, their uncritical construction works to reinforce norms of behaviour that enact the second phase of disciplining by inviting 
comparison and self-surveillance by the population (Schirato et al. 52). The uncritical dissemination of systems of knowledge work to produce the word in a certain manner, naturalising a certain way of acting and thinking, and causing other ways to be framed as unimaginable, abnormal, or a sickness (Brady and Schirato 8; Bouchard 24; Foucault "Interview" 283). The circulation of such discourse is fundamental to the exercise and strengthening of power, as speech is a key mode of communicating social learning and disciplinary norms, such as which experiences we should prioritise, and how to organise them into our personal life histories (Hartley 1; Foucault "Two Lectures" 31). While Campbell Live provides a point of rebuttal and criticism to normalisation and panopticon surveillance in hard news stories, commercial imperatives lead to the inclusion of 'educational' forms of selfimprovement in soft news stories that give the audience the "tools to use against itself" (Schirato et al. 53). Television's moving images lends news stories greater immediacy and authority, and thus the norms which are prioritised on Campbell Live are compelling and likely to succeed, propagating discourses of truth through these acts of communication (Foucault "Two Lectures" 31; Thussu 19). Uncritical dissemination encourages subject's to see these norms as natural and inevitable, and then evaluate themselves and others in terms of these norms (Foucault "Two Lectures" 44; Schirato et al. 53).

A common norm in contemporary Western society is the myth of women as innate mothers, having great knowledge of children. When Campbell Live broadcast a segment on child safety in cars, the 'expert' was prioritised as a mother through her introduction as "Laura Hall, a mum and child restraint expert" ("6 April" Campbell Live 02:02). Hall was then shown demonstrating 'proper' use of a car seat on her own three year old child ("6 April" Campbell Live 02:39). While Hall was labelled as an expert, there were no credentials given to support this claim, and she was not interrogated to prove her claims in the way that obvious power figures were. While she did provide some evidence when she stated that children are $70 \%$ safer in a rear-facing car seat, she did not say where this statistic came from, and was never questioned on her claim ("6 April" Campbell Live 02:53). Even the journalist conducting the interview was female, which framed the item as for, and relevant to, women. Women may find it quite difficult to refuse the interpellation and norms of such segments, as the repercussions for refusing the interpellation were made clear when Hall stated that mothers needed to "take the time to save your child's life" ("6 April" Campbell Live 05:14). This then frames women who refuse the norms as bad lazy mothers, a claim which was not subjected to critique. Indeed, both John Campbell and the journalist in control of the piece 
were barely seen throughout the story, prioritising Hall's information over a critique of her claims.

This uncritical approach is further reinforced by host John Campbell's engagement with soft news segments, his manner of presentation and bodily movements operating quite differently when he is engaged in a performance of public sphere critique to when he is introducing a soft news story. This performance and use of bodily hexis not only works to produce John Campbell's own subjectivity, but also serves to cue and interpellate viewers. The use of John Campbell's bodily hexis to cue and interpellate viewers to active, critical engagement was clear when he questioned Paula Bennett, Minister for Social Development, about a government 'crack down' on benefit abuse (“23 March” Campbell Live). John Campbell's body language was sceptical, as he leant back when he was talking, spoke formally, and between looking assertively into the camera glanced down at a prepared sheet of information ("23 March" Campbell Live 02:26-03:44). This performance framed John Campbell as a serious member of the public sphere, armed with research and knowledge to be deployed in rational debate, while Bennett was openly framed as a power representative who required rational interrogation.

In contrast, when John Campbell introduced a story about a couple about to celebrate their $76^{\text {th }}$ wedding anniversary, he leant across his desk towards the camera in a relaxed manner, smiling and talking in a gently jovial tone. After he announced the length of the marriage, nameless unseen people in the studio started cheering and John Campbell grinned and punched the air ("16 March" Campbell Live 08:53). This more relaxed bodily hexis signals to the audience that they needn't bother engaging with the piece in a critical manner, despite the celebration of the couple's $76^{\text {th }}$ wedding anniversary implicitly condoning and prioritising long-term, monogamous, heterosexual relationships. The couple are asked many times what their secret is to "keeping the love alive" - also the title of the story - which strongly presents a norm to the audience.

While this may seem to go against the rational discussion of political issues that the public sphere purports to prioritise rational, critical discussion is often not as popular, and therefore profitable, as human interest, crime, or celebrity (Thussu 15; Corner and Pels 2). Commercial pressures impel Campbell Live to include popular stories in order to retain audience, and by including pieces that reinforce norms Campbell Live avoids being too threatening, and losing audience through an overly pessimistic structure (Crofts 269). The preservation of audience is crucial, as television is dependent upon ratings and the advertising that ratings attract (Thussu 21). The soft news stories are effectively a bargaining chip, attracting audiences and 
advertisers, and enabling the continuation of the programme without which the critical hard news stories would also be lost. The balancing of journalisms role as the major enabler of the modern public sphere and commercial requirements for an audience is therefore quite relevant to the continuation of the public sphere as a whole (Anderson et al. 5).

\section{The Expansion of the Conventional Public Sphere}

Campbell Live is therefore a conflicted space, producing itself first as a public sphere site of critique and resistance yet still working as a site for the propagation of norms and the tools for self-surveillance by the population. These conflicting functions demonstrate the instability of power relations, as although Campbell Live critiques aspects of society the programme must also serve as an expression of dominant aspects in order to survive in a commercial setting (Foucault "Two Lectures" 36; Crofts 271). Campbell Live therefore serves to both propagate dominant discourses and negate them. These conflicting discourses and functions are not necessarily impossible for the programme to reconcile, as each challenges and cross fertilises the other (Holland 220).

The relaxed presentation of norms is in soft news stories is more complex than a simple infliction of power. The body language that is adopted during soft news pieces is meant to ensure that viewers like John Campbell, no matter how bad the hard news that he delivers may be (Bell 25). A subject's bodily hexis is both inflected by and reproduces the cultural fields that they are part of and identify with, representing their identity through bodily performance (Brady and Schirato 9; Foucault "Two Lectures" 36). John Campbell produces himself as a personification of the news sphere and a centre point for the programme in this manner, as a rational, disinterested, serious male body has great cultural capital within highly valued cultural fields such as science and journalism (Brady and Schirato 11; Anderson et al. 5). Yet in the soft news segments John Campbell's more relaxed manner is a move away from the "stilted, contrived, and lifeless accounts that seem to disengage people from their own communities" (Anderson et al. 5).

John Campbell's changing performance is typical for current affairs show hosts, who alternate between a serious and knowledgeable demeanour to personifying elements of the perceived target audience in order to anchor and mediate the many different stories that are discussed (Hartley 90). While the trade off for this is a reduction in the critique of the discourses circulated through soft news stories, the use of a more personable, narrative driven style broadens the public sphere, creating interest and engagement from viewers who were previously excluded, and therefore disenfranchised (Anderson et al. 6; Simons 181). 
Commercial demands for audience retention and entertainment thereby push Campbell Live to address more citizens (Holland 220).

Yet these soft news items perform an important democratic function that goes beyond mere audience retention. While the soft news segments on Campbell Live have problematic elements, they serve to actively draw audiences into the public sphere and ensure a "universality of appeal" that is important (Thussu 24; Couldry et al. 3). There are so many news outlets available that many citizens are swamped by an "information overchoice" that most subjects do not have the time or inclination to process (Anderson et al. xxi). Creating an interesting public sphere is therefore crucial enabling citizens to engage actively (Anderson et al. 7). Overly pessimistic, doomsday content can lead viewers to become cynical and disengaged from the news sphere, but the inclusion of entertainment and unconfrontational elements attracts these disengaged viewers to Campbell Live, thereby facilitating a renewal of engagement with critical segments (Anderson et al. 4). By providing some light relief, Campbell Live entices viewers to the programme, who will then engage with critical items, and partake in a previously overwhelming public sphere (Anderson et al. xxi). While the child safety piece may reinforce problematic gender norms it does at least serve to invite women into the public sphere, which is highly relevant because of Western society's long history of excluding women from public political life (Foucault "Sex, Power"). Thus the inclusion of casually engaging soft news is significant for not only the retention of a politically engaged audience, but their active recruitment.

Despite Campbell Live promoting certain meanings it does so in a widely accessible format, leaving the programme's preferred meanings open to contestation. Viewers do not even need to be literate to understand the programme, and to actively participate through the 'Your Opinion' section requires only literacy and a computer. This further reinforces Campbell Live as a space that prioritises "universality of availability" as a core principal (Thussu 24). In interpellating a wide potential audience to respond actively to news stories, Campbell Live encourages resistance as an active practice (Foucault "Space, Power" 165).

Indeed, by offering the 'Your Opinion' section in each show, Campbell Live arguably celebrates differing viewer opinions that work against the circulation of dominant norms, even those that authorise the field of journalism. Although John Campbell clearly approved of the two men who vandalised the Waihope spy base and provided an example of critical speech and action, the viewer feedback that John Campbell displayed and read out evidently opposed his positive response, calling their defence "typical legal mumbo jumbo", and asserting "no wonder our youth are so confused” (“17 March” Campbell Live 10:42). 'Truth' 
is constantly pursued and rewarded, and Campbell Live demonstrates the overriding access to power that truth claims possess in prioritising an appearance of truth over an image of journalistic infallibility (Foucault "Two Lectures" 31; Foucault "17 March" 416). While the producers could have chosen not to have publicised a letter that so clearly contradicted John Campbell's framing of events, doing so embraces the notion of diverse viewer opinions and further encourages critical thought and speech.

This need to draw citizens into an inclusive, engaged public sphere further explains the signalling of national identity. While people in a nation-state can be separated by categories such as religion, class or age, the promotion of a shared commonality through national culture makes these varied individuals able to be interpellated as a cohesive group of political subjects (Schirato et al. 57; Anderson 254; Gupta "Blurred Boundaries" 227). Nationality is used as a meta-field, a site of communal culture which authority figures encourage and enable because it assists the toleration of change by providing a continuity of meaning and culture to embed subjectivities within (Schirato et al. 56; Gramsci 81). Campbell Live must appeal to a wide base, and deal with many different stories and levels of public sphere activity in a short period of time. By appealing to a wider communal culture, John Campbell interpellates the audience to respond to a cultural field with rules that they are familiar with and unlikely to refuse when its membership is framed so positively.

Campbell Live incorporates nationality into many of the formal elements of the programme. The title sequence that starts the programme culminates with an image of a glass-like New Zealand overlaid by the "Campbell Live" title, connoting the programme as a nationally defined public sphere. John Campbell then incessantly signals national identity through the discourse he uses throughout the programme, and the programme also closes on the same graphic of the New Zealand islands overlaid by the Campbell Live logo that opened the programme. The news events are thus shown as distinct events, but embedded in a wider cultural field, which creates a text that provides a representation of how cultural fields are embedded in the wider socio-cultural context.

Visual culture presents power structures with a valuable opportunity to manipulate public opinion and emotion, thereby smoothing the way for the exertion of power upon the population (Thussu 20). Using visual culture to reinforce a common culture in the form of national identity is a key method of controlling populations and perpetuating the state (Schirato et al. 57; Gupta "Blurred Boundaries" 227). While contemporary individuals construct themselves as belonging to diverse identity groupings, the dissemination of 'national culture' helps to give the population evidence of shared traditions, ideologies and 
values (Schirato et al. 57; Gupta "Blurred Boundaries" 227). Encouraging investment in a national identity helps to discipline populations into adhering to certain behaviours that are framed as part of this identity (Schirato et al. 57). It also gives individuals the grounds to believe that they identify with others of their nationality, and a meta-culture for other cultural fields to work within and draw upon (Schirato et al. 57; S. Turner 91).

However, while national identity can be used as a method of social control, it also promotes social cohesion and understanding between groups (Thussu 24; Anderson 257). The audience is gathered together as if they have something in common, and then given something to react to and discuss together (Anderson et al. 11; S. Turner 91). This helps smooth discussion and critique of news events, by providing a common ground between participants. Campbell Live interpellates viewers as national citizens in a way that is difficult to refuse and able to be colonised by power, but that also serves to sustain the resistance of public sphere critique. When discussing the possibility of mining on conservation land John Campbell references New Zealand's brand as "100\% pure", but then states that "beneath the Lord of the Rings" scenery" is mineral wealth that could raise the standard of living ("22 March" Campbell Live 00:25). He then continues to say that New Zealanders are torn between preserving "what makes us unique", and envy over the wealth generated by mining in the "much less beautiful” Australia ("22 March" Campbell Live 00:25). By framing the debate in such a manner, it makes it difficult for viewers to refuse to be interpellated as proud New Zealanders who have something at stake in this debate. The widest possible audience is thus invited to actively participate in the critical public sphere that Campbell Live constructs through their interpellation as invested subjects.

Such elements are highly important to Campbell Live's position as a public sphere space. The production of these subject categories is always dependant on the context of time and place, and the interpellation of viewers as good, responsible citizens is extremely dependant on the framing of Campbell Live as an explicitly politically motivated public sphere (Schirato et al. 55). 


\section{Chapter 4: Shortland Street Results}

\section{Soap Opera as Feminine Public Sphere}

Television is an important contributor to the public sphere, providing information and narratives that prompt discussion between audience members (Dahlgren 411). Yet it is a public sphere that uses a mass broadcast medium to blend into the routines of the home, often being watched while domestic life continues (Casey et al. 86). Soap opera is the genre that most explicitly embraces television's crossing of the public and private divide, negotiating the boundary of the public and private spheres and encouraging public sphere discussion to be informed by emotion and experience that is usually deemed private (Geraghty "Study" $318)$.

Soap opera was initially created for radio with the aim of attracting a female audience for detergent companies (Bowles 188; McCarthy "Studying" 47; Casey et al. 222; Hobson 7). The genre's focus on family, personal relationships, moral issues and emotional matters was thus a deliberate attempt to relate to female housewives, and as a method of "working through' problems which was prioritised over discourses of factual rationality (Bowles 188; Silverstone 73). Soaps were broadcast during the day and structured as background for a woman's domestic tasks by emphasising sound, which further enabled the distracted viewing style of television (Bowles 122; Casey et al. 87; Silverstone 73). The programme's sponsorship by detergent companies such as Proctor \& Gamble is what led to the inclusion of 'soap' in the name, the further addition of 'opera' serving as an ironic misnomer that indicates the low cultural status often assigned to the genre (Bowles 188; McCarthy "Studying" 47; Casey et al. 223). The name itself therefore indicates both the perception of soap as a feminine sphere and the need for such a gendered space, as the cultural products of disempowered groups are less valued than those of culturally dominant groups (Fraser 495).

Soaps are a staple in broadcast schedules worldwide because they are typically inexpensive to produce, structure the audience into a habit of daily weekday viewing, and are often successful enough to continue for decades (Bowles 188; Casey et al. 223; Seiter and Wilson 136; Geraghty "Study" 310). This is certainly the case for Shortland Street, a New Zealand soap broadcast week nights at 7pm on TV2. Shortland Street debuted on May 1992, and has a dependably large audience that has helped the programme break records for its popularity and regularly capture more than half of the audience for its timeslot (Lealand "Quality Television" 133; Dunleavy 41; Lealand "Regulation" 217). Shortland Street is 
clearly a soap opera because of its ongoing, interwoven storylines that develop over many episodes, its specific and familiar locations, and wide range of established characters that form the core cast (Hobson 33). The multiple storylines are dialogue driven and use controversial issues to engage the audience, cliff-hangers and deferment of resolution are used frequently, and the programme is broadcast each weekday (Hobson 33). Visual features such as an intensified use of close-ups are combined with this emphasis on the personal to create highly charged emotive storylines (Casey et al. 154). These characteristics give Shortland Street the potential to contribute to the public sphere in a meaningful manner by supplying regular and entertaining information, and using characters that start discussions between audience members (Hobson 160).

These genre characteristics cause soap to discuss issues from a point of view that prioritises emotion using the public sphere to deal with private issues of the personal, emotional and feminine. Habermas's initial conception of the public sphere explicitly denigrated the use of emotional narrative, which he viewed as an impediment to political discussion (Briggs 6). As such, the public sphere usually carries connotations of the masculine, rational, and informative, yet viewing only one discourse as valid narrow the public sphere to exclude certain citizens (Dahlgren 419). Indeed, a wholly rational public sphere works to reinforce current power structures, the construction of public sphere communication as requiring emotionless rationality working to nullify the potential for mass opposition (Murdock 177). Rationality individualises citizens, and in overemphasising rationality it becomes a power relation that reduces the potential for the coming together of citizens to demonstrate an urgent need (Murdock 177). While Habermas feared that emotional discourse would destroy any chance for rational debate, shock and identification are important reactions for creating understanding and investment in the viewing public (Briggs 7). Emotional public discussion is a mode of communication that is necessary, but culturally denigrated because of these power relations.

This blurring of the public and the private creates a space for those who are disadvantaged by more traditional public spheres, particularly women in the case of Shortland Street (Dahlgren 425). Despite Shortland Street's use of the hospital workplace to generate narrative, it remains true to the central soap concept of drama that focuses on the family and how family survives the various crises that assail it (Hobson 116). Shortland Street uses this family structure to promote debate among viewers, by combining the family unit's relatable nature with a talk focused narrative that works through controversial storylines (Casey et al. 224; Geraghty "Study" 319). While soaps have attracted many demographics throughout its 
history, the focus on the personal, the community and domestic spheres, and its gendered style of address, has lead to a perception of soap as a feminine text (McCarthy "Studying" 48; Casey et al. 206). Shortland Street thus utilises mass broadcast for public sphere discussion from an alternative viewpoint, usually one that promotes domestic feminine discourses and values, the daily broadcast giving viewers the opportunity to participate in this alternative public sphere regularly (Dahlgren 427). This regular broadcast and use of discourses that are perceived as feminine works to cultivate potential for an increase in women's social power (Foucault "Sex, Power" 168). The controversial and current subject matter then cements Shortland Street's public sphere role.

This representation of feminine issues within a feminine perspective was visible in Shortland Street's storyline about teen pregnancy. The young characters Daniel and Loren were still living at home, and had barely started university, when Loren accidentally became pregnant. This storyline is particularly significant because Loren was a very independent character, working to support herself and forming strong opinions that she voiced frequently, one of which was a disbelief in romantic love. This rejection of romantic love was central to Loren's position as a role model for independent women, as Western notions of the family rely on the ideology of romantic love to justify and reinforce the economic and emotional dependence of women in a heterosexual relationship (Brown 27).

When the pregnancy was discovered Loren initially wanted to terminate it, but was temporarily persuaded to keep the baby by Daniel and Loren's father Reuben. This storyline had the potential to convert a previously strong character, trapping her into the economic and emotional dependence that she had previously resisted. The discursive constructs of romance and the family are a significant method of controlling women, and media representations proliferate these discourses (Brown 37). However, the female community of Shortland Street overcame this potential problem, as Loren eventually decided to terminate the pregnancy with the support of Daniel's mother Sarah and community member Brooke. Shortland Street portrayed their female characters as empowered and able to use their oral networks to both learn of what Loren was facing and to support her. Many of the female characters made strong arguments for Loren having a choice, and needing to do what was right for her.

Soaps prioritisation of women is significant, as there is a gender imbalance prevalent throughout much of the television landscape. In the US, there are three times as many men on television as there are women, and the roles that are available to women tend to be quite limited and prioritise youth (Casey et al. 49). British television tends to be similarly biased (Casey et al. 49). Issues of access and gender imbalance is not a new phenomenon brought 
about by the mediated public sphere, but one that is even visible in Habermas' 'ideal' coffee shop public spheres, that were only available to men of the upper classes (Silverstone 67; Schirato et al. 113). Soap ensures the presence of a female perspective within the public sphere by combining these current and controversial societal issues with a method of storytelling that promotes the domestic and personal (Geraghty Women 195; Zoonen 102). Casts are often predominantly female, and portray family, community, and personal relationships, all of which are strongly associated with feminine experience (Geraghty Women 196; Zoonen 102).

Soap not only acknowledges the existence of women, but prioritises feminine spaces, issues, and points of view (Geraghty Women 196). It uses and solidified feminine discourses, ensuring their presence within the mediascape and attracting viewers who are disenfranchised by the structures of other genres (Brown 1; Alasuutari 6; Neale 1). The use and naturalisation of feminine and feminist discourses equips viewers to conceptualise and verbalise ideas in new ways, creating the potential for resistance through the promotion of alternate modes of thought (Brown 8; Foucault "Sex, Power" 168). This has made the soap genre important to discussions of gender, the alternative emotional subject matter and discourses used by Shortland Street working to negate the marginalisation of woman in the public sphere by employing the characteristics of the private sphere to frame discussion of social issues on a public medium (Fraser 494; Seiter and Wilson 136).

The use of emotion, rather than reason, as a guiding force is a leading reason why soap is so strongly linked to low culture, and seen as threatening by those who would assume the position of moral guardianship (Casey et al. 155; G. Turner "Studying Television" 4). However, Shortland Street is an important counterpoint of diversity to traditionally rational spaces of discussion, as a disproportionate focus on rationality structures discussion in masculine terms (Fraser 491). Emotional responses are a significant component of human processing, and make stories relatable and universal, and draws audiences into the discussion (Hobson 161; Simons 179). The rational, serious discussion that news prioritises is important, but when used too often fosters disengagement from viewers (Anderson et al. 5). Narrative driven stories that are related in a personal manner generates interest and engagement from audience members that were previously excluded from the public sphere, and the increased understanding and empathy that soap cultivates provides a basis for audience members to relate to issues (Anderson et al. 6; Couldry et al. 33). This use of emotion not only marks soap as an explicitly feminine space, but is a way of increasing audience engagement with 'social issue' storylines. 
Through these techniques the soap opera genre embodies the public sphere functions that television is most capable of filling. Promoting discussion along a breadth of social and personal issues gives Shortland Street an important role in the involvement of citizens in the public sphere (Casey et al. 224). The time constraints of television are reduced by the use of narrative rather than complex information that requires time for context, and the framing of issues in terms of daily routine (Silverstone 52; Webb et al. 188). The issues and values that soap opera represents through narrative are similar to the domestic setting that television viewing is integrated into, thereby smoothing the transition of public issues being broadcast into private homes (Bignell 172). This allows soap to reflect current areas of interest back to the audience, whether these areas be simple moments of daily life, or hot topic concerns (Hobson 139). Despite Shortland Street's early evening timeslot, it frequently includes stories that address contentious issues, including "race relations, gay relationships (male and female), infidelity and divorce, drug and alcohol abuse, crime and criminal manipulation, out-ofcontrol teens, medical misadventure - as well as the usual births, deaths and marriages" (Lealand "Quality Television" 134).

These current and controversial narratives mirror the blurring of the public and private that the television medium itself enables, using the home environment as a setting for the discussion of wider issues, thereby domesticating public issues, and bringing the domestic into public life (Casey et al. 86; Silverstone 68; Slade 32). This contests traditional public sphere values, reconstructing personal issues as acceptable for public sphere discussion and personal sphere discourses as a valid method of critiquing public events (Couldry et al. 8). Soap's emotionally based presentation of issues engages the audience in a manner that prompts active discussion and involvement, despite traditional public sphere prioritisation of the rational, thereby actively reconstructing meanings and the conditions that power is exercised through (Geraghty "Study" 311; Foucault "Sex, Power" 168).

The multiple interweaving narratives of soap reinforce the preoccupation with the personal that ensures an alternative public sphere, but requires a large cast of regular characters to work (Geraghty Women 133; Bowles 122; Casey et al. 224). This cast also needs to be connected and to interact, functioning as a community that is more tight-knit than other genres would demand (Bowles 122; Mumford 18; Dunleavy 43). The community feel of soap is then reinforced by the narrative unfolding at a pace that mirrors the viewer's daily life; the daily instalments of a soap are often presented as if they also happen over the course of a day, and specials are usually featured to incorporate national holidays such as Christmas (McCarthy "Studying" 47; McCarthy "Realism" 53). Soap's regular characters and ongoing 
plots that centre on personal and domestic experiences combine to invite audience members to the playful belief that the soap opera world continues as a real community would, and that viewers participate by sharing their lives (Hobson 2; Casey et al. 194; Slade 70). Soap opera's illusion of continuance adds credibility and realism to the narrative and invites the viewer to a particular community (Hobson 2). This community aspect, when combined with the previously discussed prioritisation of the female, constructs a connected female audience that poses a threat to dominant systems (Brown 19).

The familiar settings of a regular coffee shop, workplace and bar in Shortland Street are relatable to viewer's own lives, providing a comforting experience that most viewers find enjoyable (Casey et al. 154; McCarthy "Realism" 53). This mirroring of a viewers daily life not only provides a point of familiarity for the audience, but provide realistic ways for characters to regularly run in to each other and be connected to each other (Casey et al. 225; Bignell 161; Dunleavy 43). Everyday language and colloquialisms are used, and commonplace settings that will have a sense of familiarity to most viewers (Casey et al. 86). Shortland Street thus creates a community that strives for the community haven that viewers are likely to idealise, while the imperfections and crises that assail this community assures the viewers' inability to create this community haven in their own lives (Dunleavy 42). Neighbourhoods, families, and small towns become the focus of many soap operas because of their ability to create the right type of narratives, and these settings in turn reinforce the narrative's preoccupation with personal interactions (Bowles 122). This frames Shortland Street as a wholly familiar and reassuring space.

This large, community based ensemble cast also stops Shortland Street from itself becoming a narrowly focused and exclusionary space. Although the teen pregnancy storyline prioritised female empowerment through the response of the community and Loren's actions, the programme avoided losing viewers by utilising the ensemble cast. A valid public sphere is required to not only allow the expression and formation of varied opinions, but also to transmit the information and discussion to other citizens (Schirato et al. 113). Representative debate is achieved by different characters taking up different viewpoints of varying intensity, shown when many characters argued with one another about Loren and Daniel's situation (Fraser 490). Several of the male characters argued for Daniel's right to keep the child that he had fathered. The programme thus avoided accusations of promoting abortion, as it included extensive discussions of the many viewpoints and values involved in such a situation. Indeed, this also serves as a point of resistance for men, the portrayal of their active discussion in 
personal sphere matters constructing them as part of the personal sphere that they are often culturally excluded from (Gauntlett 10).

The diversity of viewpoints and problems in soap are able to be presented to the audience precisely because viewers are intimately familiar with the characters involved (Hobson 35). This familiarity allows the audience to connect to the story and the experiences of the characters, and created the potential for sympathy and greater understanding, even if the audience has no direct experience of such events (Hobson 142). It also avoids alienating audience members who disagree, which would both impact upon Shortland Street commercially and limit its public sphere role. While soap operates in a predominantly commercial landscape in which the construction and retention of an audience is paramount, a key secondary force is the drive to bring social issues to the forefront of the audience's consciousness, and there needs to be a wide audience for this to be effective (Tulloch 161). The retention of a diverse audience allows female concerns to be presented to viewers who have no experience of them (Gauntlett 2).

While soap opera is often criticised for its unrealistic depiction of events, it is the emotional realism in the characters reactions to and debate of these events that retains an element of authenticity that ensures a level at which the audience can relate to the narrative (McCarthy "Realism" 50; Slade 70). The portrayal of Loren's confusion and Daniel's distress made it difficult for audience members to condemn their actions, instead promoting empathy for their predicament. Arguments between the characters were often communicated passionately and informed by personal experience, making it difficult to condemn the expression of opinions that audience members could easily find offensive. This prioritisation of emotional realism is important for any serious study of the genre, to understand how audience members are able to take so seriously a genre that is often seen as frivolous and superficial (McCarthy "Realism" 50).

Although these patterns of discourse focus upon the personal and domestic, once taboo for public discussion, private concerns are now recognised as impacting upon public issues, and public issues as having personal relevance (Hobson 161). Indeed, concealing problems of the personal sphere from public discussion serves to empower dominant groups, as inversely demonstrated by the strength that Loren drew from the female community to get the abortion that she wanted (Fraser 503). The soap audience is thus interpellated into a community that has the tools for active practices of resistance as the public sphere that Shortland Street provides is one that raises topics and viewpoints in a manner that provides a starting point for audience members to practice their own resistance through discussion, and a "working 
through' of public sphere issues (Dahlgren 420; Foucault "Space, Power" 165). Viewers are made aware not only that an issue exists, but that it is common enough to warrant inclusion in television narrative (Brown 19). This promotion of working through as a method of civic engagement is crucial to audiences forming opinions that are then drawn on in other areas of political engagement (Dahlgren 420).

While it is not true that soap opera appeals only to women, it is true that it is generally designed to prioritise women and relate stories in a 'feminine' manner (McCarthy "Studying" 48). Shortland Street has a loyal young female audience, and this is reflected in the construction of its narratives and discourses, prioritising a female mode of understanding and requiring competency in feminine modes of communication (Lealand "Quality Television" 136; Geraghty "Study" 315). Fostering a sense of engagement and investment in the public sphere is important for an informed and active citizenry, and soap's use of interweaving storylines and an emphasis on the personal and emotional does just that. Even if audience members are uninterested in one of the storylines, there are other storylines that may be more successful in engaging the viewer (Casey et al. 224). Although there is often an implicit assumption in public sphere theory that citizens are eager to participate in the public sphere in any way that they can, this is often not the case (Dahlgren 413). The portrayal of Loren's pregnancy and subsequent termination was one which viewers could potentially have had difficulty with, and the inclusion of other storylines ensured relief from the emotional tension, and prevented disinvestment during a difficult topic.

\section{Discourses of Hysteria}

While soap is a public sphere with the potential to personalise issues and explore how they work in practice, the representation of these issues can be hampered by soap's overly dramatic style which serves to further problematise the issues it seeks to address. Problematising human behaviour frames it as something that needs resolving, and makes it vulnerable to the exercise of power (Foucault "On Power" 106). Sex is a subject that is particularly central to bio-power, and since bio-power's ascendancy discourses seeking to control and censor sexual relations have multiplied (Foucault "Incitement" 492). The Western construction of sexual identity of being at the core of an individual combines with soap's prioritising of the personal sphere to the predispose the genres to using sexual relations as a source of drama and narrative force (Hobson 128; Foucault History of Sexuality 61). While female sexuality is often framed as threatening, soap generally presents female sexuality as enjoyable, able to be controlled by women, and as being available to characters such as older 
women that are often denied being sexually desired or desiring (Casey et al. 217). In more recent years this theme of sexual empowerment has widened to include more controversial sexualities (Hobson 128). Sexual relations are liable to create emotionally charged disaster, and the inclusion of a gay relationship increases this potential for dramatic storylines and the attraction of audience demographics that are interested in gritty emotional fare (Hobson 130; Hopkins 136).

Included in Shortland Street's range of characters is a lesbian couple, Maia and Nicole. The inclusion of lesbian identity is attractive for Shortland Street, allowing an interesting aspect of difference because of their sexuality while ensuring that the difference is within the familiar bounds of personal relationships (Geraghty Women 157; Hobson 144). Historically Shortland Street has shown lesbian relationships as problematic, riddled with denied sexual tension and without the moments of calm domestic happiness that heterosexual relationships are shown experiencing (Hopkins 99). Maia's previous relationship with Jay was represented in a manner that bordered on sexual tokenism and portrayed their relationship consistently unstable and problematic (Hopkins 140). While inclusion of Maia and Jay did allow exploration of issues of intolerance, lesbian identity was constantly framed in terms of the problems that it caused them. Popular culture offers templates not only of desirable identity but of the undesirable that citizens should avoid, and such representations work to put lesbian identity outside of norms, influencing viewers both to resist any urges towards lesbianism and to correct other people who seem in danger of accepting lesbian identity (Foucault "On Power" 106; Ransom 17; Schirato and Webb 148). Lesbian sexuality became the defining aspect of Jay and Maia's identities, and was clearly undesirable.

This aptly demonstrates Foucault's point that explicit political power is neither the only nor the most important form of power, but rather that contemporary power relations are exercised through knowledges and norms that are constructed as natural (Foucault "Intellectuals" 213; Foucault "Two Lectures" 44; Ransom 14). While homosexuality may no longer be illegal in New Zealand, legal changes only make equality possible and by no means guarantee a meaningful impact upon daily life (Beauvoir 338). By framing lesbian relationships as inherently difficult and unstable Shortland Street portrays lesbian identity as unfavourable and abnormal (Foucault "Interview" 283). These representations then connect with the network of other narratives disseminated about lesbian sexuality, both mediated and otherwise (Briggs 9). The inclusion of their relationship resisted some exercises of power that seek to mute frank sexual discussion, but the problematic framing reinforced power relations that are exercised through the construction of the abnormal (Foucault "Incitement" 493). 
Maia's relationship with Jay eventually ended, and bisexual character Nicole was introduced. Shortland Street portrayed Nicole and Maia very differently, and their relationship is a prime example of a soap opera handling an issue in a manner other than superficial hysterics. Although the initial relationship between Maia and Jay focused on sensationalist issues, her current relationship with Nicole is constructed as background and familial. The couple live together in a stable relationship that is accepted by the rest of the cast. During the period of study their relationship was itself unproblematic and functioned as a background to other storylines. While Nicole and Maia's very low level of physical affection displays could be interpreted as a method of masking their relationship to viewers who are uncomfortable with it, familiarity with the soap genre shows that this is quite common for any couple in a soap opera. While there is a focus on sexual relations, physical displays of affection such as hugging and kissing are rarely seen in soap and sex is often only alluded to or implied, which is in keeping with soap's talk driven narrative and familyoriented target audience (Hobson 129). Therefore, Maia and Nicole's low level of physical affection for each other only serves to further emphasise their inclusion as a normal couple. That their relationship now attracts little attention and is represented in a similar manner to heterosexual couples serves to frame lesbian sexuality in a positive light, but it took long term inclusion for this to be possible.

Shortland Street's portrayal of Nicole and Maia's relationship is particularly relevant in light of soap's reputation as a feminine genre. Although soap opera has tended to welcome the inclusion of gay male characters, lesbians are scarce (Geraghty Women 158). Inclusion of lesbian characters is challenging because of the celebration of femininity that is so central to the soap genre (Geraghty Women 158). While a community based on female values and strong female relationships may seem the ideal ground on which to base discussion of lesbian relationships, it is this background that makes the inclusion of lesbian characters "genuinely subversive, implying that lesbians are not separate from, indeed [have] things in common with, other women" (Geraghty Women 158). For a lesbian relationship to be introduced to an environment of strong female friendship calls into question the other female relationships that much of Shortland Street is based upon. Lesbian relationships also problematise the domestic setting that soap prioritises, as a career woman with a female partner is almost entirely removed from the family realm (Geraghty Women 158).

Shortland Street neutralises this potential issue by creating a strong family network around Maia. Maia has a close relationship with her mother Yvonne and her two sisters, all of whom work with her at Shortland Street hospital. These relationships allow Maia strong friendship 
without sexual undertone, keeping her within the feminine personal realm that soap prioritises. Maia's role as a mother ensures she stays within the domestic realm. Although her son was conceived by a sperm donor and is rarely seen, she is often asked about her son and is shown trying to fit her work schedule around her obligations as a mother. By showing Maia dealing with common problems of work and motherhood Shortland Street ensures she remains relatable, and although she now has female partner Nicole the problems that they face tend not to be specific to lesbian couples. Maia is kept within the bounds of New Zealand norms of femininity, as she is slim and attractive, with maternal instincts and a compassionate nature (Hopkins 92). She is thus reclaimed as a 'real' woman, who happens to be a lesbian, acting in a manner that is reassuringly expected and concurrent with the norms for her gender (Smart 104). However, her inoffensive and portrayal that invites identification is what creates subversion by showing her as a woman, rather reducing her to her sexuality (Geraghty Women 158).

Indeed, Maia is the legitimating force in the relationship, the unthreatening portrayal of lesbianism as an unproblematic aspect of the community. She is 'straight-acting' and inoffensive, and thus easily reclaimed as the 'lesbian next door' that viewers can identify with (Hopkins 138). Maia is easily integrated into the mainstream due to her typically feminine appearance, and is frequently pursued by male characters which textually acknowledges the possible desire of male audience members to ignore her lesbian sexuality (Hopkins 142). While Maia may have a non-normative aspect of her identity, she is still a productive citizen who is useful to the state, working hard at the hospital and taking the responsibility of raising her son seriously. Maia cares about doing well in her job, and is complicit in monitoring Nicole, encouraging her to be more responsible. As such, Maia is enmeshed in panoptic surveillance of both herself and others, and displays characteristics of good citizenry that enable her lesbian sexuality to be overlooked (Schirato and Webb 133; Ransom 17). She becomes a desirable template, of which her sexuality is only a part.

This neutralisation of Maia is necessary for enabling soap's function as a feminine public sphere, but it also neutralises a chance for subversion. However, subversive elements are retained by the inclusion of Nicole, Maia's female partner, who is not framed as comfortingly. While Maia's difference is almost completely reclaimed, Nicole fits some of the characteristics of the ideal New Zealand female and not others. Nicole fits many of the stereotypes of the challenging lesbian, with shorter hair and a selfish nature that is sometimes rude and arrogant (Hopkins 94). Yet Nicole is not completely othered, as she is a loyal friend, femininely attractive, and the trouble that she causes is usually through a lack of forethought 
rather than maliciousness. As such, the audience may not be completely comfortable with her character but are also unlikely to completely reject her. In this blurring of boundaries Nicole has the potential for subversion, submitting neither to heterosexual desire nor the role of demonised 'other'.

This makes Nicole a more contentious character than Maia and a point of diversity, within Shortland Street. She refuses to mould to the power systems of the hospital or to enter the cycle of monitoring herself and others to ensure behaviour is in line with norms of productivity, working against the successful exertion of disciplinary power by prioritising fun over responsibility. This positions Nicole firmly as an active and friendly member of the community; she not only refuses to completely submit to disciplinary power, but actively contributes to the portrayed public sphere community. This inclusion of Nicole as a subversive character is only possible because of Maia's long-term inclusion and unproblematic framing, and Nicole's disposability should the audience find her too confronting.

\section{Overcoming Hysteria Through Gossip}

Maia and Nicole thus exemplify how the soap genre works as public sphere. Maia serves to reinforce conventional values, while Nicole is ambiguous, unstable, and disruptive. This is possible because of Maia's role as the safe representation of lesbianism that is embedded within the soap community, while if Nicole's subversion goes too far she is disposable, because she is not strongly tied in to the community by family. Nicole becomes a template for the active practice of resistance; of norms, of the desirable, of discipline, and even of definitive categorisation. This representation works against the status quo, producing a small opportunity for resistance and legitimating Shortland Street as a valid public sphere site (Schirato and Webb 190). The pairing of Nicole and Maia allows Shortland Street to finally include lesbian sexuality in a meaningful way that invites understanding of it as one part of an individual's identity, without nullifying their sexuality or homogenising their identity, but this is only possible because of the long-term discussion of Maia's sexuality.

The advantage of social concerns being dealt with in the soap format is that information can be presented in an entertaining manner that keeps the attention of viewers (Bignell 160). Soap's loyal audience base enables a higher level of visibility on issues that may otherwise only be dealt with in less popular genres such as documentary, while the long-form narrative enables depth of portrayal (Hobson 142; Dahlgren 420; Tulloch 151). These factors leave Shortland Street strongly placed to engage audience interest and promote interaction with 
difficult social issues (Hobson 142; Zoonen 112). Initial hystericising of these portrayals is difficult to avoid, as Shortland Street is required to represent changing values and norms, but in a way that is true to the identity of characters that the audience is intimately familiar with (Hobson 109). Soaps therefore often initially hystericises issues by showing characters struggling to cope with change, but over the course of long-form narrative, has the potential to contribute substantially to the discussion of social issues. If an issue survives to be discussed long-term, the combination of the large audience and use of contentious issues enable soap to contribute to competing narratives in the networks of meaning that citizens expose themselves to (Briggs 10).

The long-form communicative style of soap is the fundamental characteristic that allows the genre to meaningfully contribute to the public sphere. Soap's continuous narrative style interweaves many storylines, moments of resolution quickly leading to further storylines, and the overall narrative logic prioritising a sense of "endlessly deferred conclusion" (Bowles 121; McCarthy "Studying" 47; Casey et al. 86; Mumford 18). This famous deferment of narrative resolution has been read as a distinctly feminine narrative style, allowing loose ends rather than focusing on producing pleasure through solving character difficulties (Casey et al. 226; Hobson 23; Brown 1). The prioritisation of the female perspective is visible throughout the main styles of communication used by soap, including the focus on the midpoint, turmoil of stories, rather than their instigation or conclusion, and the previously noted high use of gossip (Zoonen 102). These narrative styles produce Shortland Street as a feminine sphere that uses marginal discourses as a mode of critique and debate.

The most obvious form of feminine communication is the high use of gossip. Within the community that soap portrays gossip is used as a narrative drive, and is also the main technique of discussion between characters (Hobson 22). Gossip is often seen as negative and trivial, but is used by soap to make sense of events and work through moral issues in a manner that is relatable for audience members (Fiske 80; Slade 78). Despite the constant threat that gossip poses to the security of the community, Shortland Street ensures the continuing promotion of community ideals by portraying characters as accepting of each other's quirks and supportive of each other in times of crisis (Geraghty Women 85). Indeed, gossip reinforces the community between Shortland Street characters and viewers, as the prerequisite disclosure involved relies upon reciprocity, interest in community member's lives, and reinforces trust and nurturing elements of a relationship (Brown 30). Problematic elements of gossip, such as gossip that can go too far and become hurtful nosiness, is often 
dealt with within the text by making overly gossipy characters the target of other character's derision (Geraghty Women 101).

These types of informal oral networks are an important method of resistance, as they are outside of established institutions and allow behavioural standards to develop through consensus between members of the subordinated group (Brown 37). When Loren was pregnant the characters involved were not idly chatting about and to her, but rather discussing Loren's options and enabling potential actions that were previously closed her. By representing this method of resistance Shortland Street offers viewers a method of working against dominant values, offering a construction of reality that emphasises female solidarity as a method of opposition (Brown 38). Shortland Street prioritises methods of communication that are typically recognised as feminine, and by portraying these networks of communication on a system of mass broadcast Shortland Street resists dominant values by making known the perspective of a disempowered section of society (Schirato et al. 118; Foucault "Sex, Power" 168). In doing so the programme gives viewers access to a discourse of truth that they can also use to empower themselves in other social circumstances (Foucault "Two Lectures" 31).

Current problems are thereby narrativised in a way similar to many viewers own style of talk, creating a practical platform for resistive discussion (Briggs 8; Foucault "Sex, Power" 168). Debate of the implications of teen pregnancy becomes a straightforward continuance of the debate between characters on the show, the narrative format thereby promoting discussion of the programme between audience members. Gossip between audience members is made less problematic by the intimate fictional narrative of soap, which provides an outlet for audience discussion of problems in a less personal manner (Hobson 31). While viewers may not want to discuss their own problems and secrets, the most intimate details of a characters problems can be discussed, and problems and solutions posed, without audience members exposing their own secrets (Hobson 31; Slade 76). This gossip between audience members produces a sense of community between those who partake in it because of its intimate nature, and also circulates feminine meanings and pleasures that contradict dominant values (Brown $32)$.

These methods of communication and discussion make Shortland Street a highly democratic public sphere as they do include a wide range of viewers, requiring no specialised training or high level of education (Simons 179). The subject matter that Shortland Street uses these discourses on further increases their importance to the public sphere. By raising an issue and providing audiences with an impersonal basis for discussion, Shortland Street gives 
viewers valuable tools for debate and resistance (Brown 19; Zoonen 102). Without these patterns of discourse to allow the expression of particular meanings and values, subordinated groups cannot articulate problems and solutions (Brown 33). The requirement for a space of public informed discussion is particularly great for disempowered members of a society (Briggs 5). Debate is recast to reflect female experience and concerns, thereby reducing their social disadvantage (Fraser 498). Access to culturally designated spaces for discussion are important for citizens to resist indoctrination in discourses of power, and words have a great deal of power to affect emotional response (Silverstone 65; Butler 499; Foucault "Sex, Power" 167). The circulation and reinforcement of such discourses is vital to an active public sphere.

Though the narrative is often full of twists and contentious issues viewer engagement is retained through consistency in values, characters, and setting, which allows soap opera to retain a feeling of the familiar and security (Geraghty Women 131). Situating a continual flood of unfamiliar stories and issues in this setting can serve to "make the unfamiliar understandable" and encourage audiences to discuss many different issues that have a bearing on political decisions (Dahlgren 430; Hobson 142). Although soap may be overly dramatic and emotional at times, this method of presentation serves to engage audience interest in subjects that may otherwise be ignored (Hobson 160). The large, ensemble casts allow for characters to have different views and experiences, thereby avoiding homogenisation or shallow portrayal (Geraghty Women 196). The multiple unresolved storylines are integral to soap's public sphere role, as by refusing to concretely resolve narrative strands soap also refuses to offer the audience the illusion of control over social concerns (Geraghty "Study" 312). This is partly what provokes discussion between audience members, and has the potential to prompt viewers to become more involved with the issues raised by Shortland Street. Any offered solutions are framed so that they not only apply to the fictional realm of the soap, but are relatable and possible to enact within the viewers own life, thereby retaining the ability to effect viewer actions (Geraghty "Study" 318).

While news may be a more explicit public sphere, the performance of objectivity and debate based upon fact is perceived by some citizens as an insincere performance (G. Turner The Demotic Turn 8). Shortland Street provides an alternative set of discourses to frame the dissemination of information and encouragement towards discussion, which some citizens have more confidence in because it does not attempt to hide narrative or the promotion of a certain point of view (G. Turner The Demotic Turn 8; Briggs 8). These issues are then portrayed through a feminine point of view through the feminine modes of communication 
used. The predominantly female audience are shown issues in practice, and given information to empower them to make decisions about their own identity and future (Brown 13). Shortland Street thus works to challenge the dominant values of what can be said and how, creating the potential for resistance by generating the possibility for audience members to conceive and speak of issues in a manner that works against predominantly masculine culture (Brown 16). 


\section{Chapter 5: 7 Days Results}

\section{Comedy as Subversive Public Sphere}

7 Days is a comedy programme that combines the news of the past week in a way that emphasises comedy over news content. Comedy is rare on New Zealand television, because of the difficulty in judging potential audience reception (Elliott 175). It is the inherent potential for critique and subversion that makes comedy an important field for this study. 7 Days has particular structural potential for a public sphere role, due to its combination of news and comedy that leaves 7 Days ideally placed to challenge existing power structures.

News and current events programmes are the public spheres that are traditionally viewed as best fulfilling requirements for dissemination of politically relevant information, and access to areas of debate where information and events are scrutinised (Murdock 178). However, the most watched programmes are often those classed as 'entertainment' (Zoonen 110; Murdock 178). It is therefore important to analyse the potential for entertainment driven programmes to fulfil public sphere functions, particularly those such as 7 Days which use news in their entertainment. 7 Days uses two teams of stand up comedians, predominantly from New Zealand but also frequently featuring international guests. The teams of comedians compete against each other by ridiculing the news, public figures, and each other. The programme is directed by Jeremy Corbett, who introduces each game, reveals the 'true' news story, and distributes points based upon which team was wittiest. 7 Days screens at 9.30pm on Friday evenings, after the voluntary watershed of $8.30 \mathrm{pm}$, thereby allowing the inclusion of 'adult' content (Lealand "Quality Television" 140). It is a site with potential to promote active citizenship by engaging audiences with the critique of politically relevant events through the use of comedy as entertainment.

The critical mindset needed for public sphere activity is maintained throughout 7 Days because of the alternate viewpoint and norm subversion is often part of the formal structure of comic utterance. The jokes used in 7 Days are quite varied, but share a fundamental reliance on comedic surprise. Surprise works by "constructing and undermining expectation, certain means and modes of playing with logic, convention, and meaning" (Neale and Krutnik 43). Comic surprise is created either by contradicting expectations that have been set up in the narrative, or challenging norms and values that exist in a subject's daily life, giving greater weight and authenticity is to the outcome that appears implausible based upon the subject's previous assumptions (Neale and Krutnik 83; J. Palmer 180). It is this implausibility 
and potential norm subversion which creates the potential for subversion of power structures. Contemporary power networks seek to construct naturalised norms, yet the punch line of comic surprise is often achieved by denaturalising these norms (Berger 127; Foucault "Two Lectures" 44; Neale and Krutnik 68).

The inherent use of incongruity to create humorous joke narrative creates an alternative manner of public sphere engagement and debate, and this pluralising of discourse is important to an open and inclusive public sphere (Neale and Krutnik 68; Fraser 494). The surprise of the punch line forces the previous joke narrative to be reinterpreted (Berger 127). While Habermas's concept of the public sphere relied upon rational debate, comedy is an important contributor to public discourse, as by decentring established norms audiences are encouraged to active resistance by examining power relations and assumptions that they take for granted (Murdock 179; Horrocks "Themes" 17). Disciplinary power sets norms that are framed as unquestionable, aiming to shape subjects and guide their behaviour to correspond to scientific standards (Ransom 17). In forcing subjects to re-evaluate norms, comic surprise problematises the mechanisms through which disciplinary power is enacted.

7 Days is hosted by Jeremy Corbett, who plays an important role in constructing the programme as a working site of critique. The role that Corbett assumes allows 7 Days to be perceived as more than slapstick humour, and encouraging viewers to engage with the programme with an undertone of seriousness. 7 Days has a highly fragmented structure, as there is no apparent overarching narrative, team members change weekly, new games are introduced often, and the order of segments is apparently random. However, continuity is provided by Corbett's role as host and judge. He is present each week, introduces and closes each game, and is central to comedic discussion. He has a minor function as a comic performer, delivering the gag that opens the show, often interjecting jokes between each segment, and sometimes joining the ridicule of news items. Yet Corbett's main role is as judge, compere, and embodiment of the programme's character. Corbett is not involved with the majority of comedic narrative, his main purpose being to provide the material that is then ridiculed by the other comedians and authorise the programme as a space of public sphere activity.

Being in the field of comedy, Corbett is able to take up a relaxed manner which frames him not only as 'one of the people', but allows him greater access to candid discourses (Bourdieu "Symbolic Power" 488). This enables Corbett to casually make fun of stories and express his feelings through facial expressions such as rolling his eyes (Reeves et al. 82). He is presented as candid and willing to comment upon absurdity, taking up the role of the 
'everyman' that viewers can identify with (Reeves et al. 82; Bourdieu "Symbolic Power" 488). Laughter changes the seriousness of news, which in itself is a defiance of the construction of news consumption as a serious chore that citizens must undertake (Brown 149). Yet Corbett is also the 'straight' man of the programme, earning the confidence of viewers by appearing dependable and rational in comparison to the farcical performance of the comedians (Reeves et al. 82; Lewis 114). The position of Corbett as a trustworthy and comedically critical everyman frames 7 Days itself as a site of political expression that welcomes the ordinary viewer, while still promoting a critical attitude through Corbett's embodiment of public sphere values (Reeves et al. 82). He frames news engagement as something that can be entertaining, yet must still be critical. This not only promotes the sphere as more attractive, but fosters a style of public engagement.

Corbett even subjects himself to comedic critique to express the importance of the ideal. While politicians are obviously powerful, power circulates through many positions and Corbett is able to exercise power through his role as host and judge of 7 Days, yet this is neutralised by Corbett working as the target of ridicule from the comedians (Foucault "Critical Theory" 128; Gauntlett 129). When the comedians were discussing Paul Henry being tricked by a hoax interviewee who pretended to be in favour of commercial whaling Corbett started to make fun of Paul Henry for letting it happen. As Corbett listed the safeguards that should have avoided the situation, a man appeared behind Corbett wearing a t-shirt that promoted a competing television show ("Episode 6" 7 Days 4:55). This set Corbett up to look like a fool, but Corbett had obviously participated in the setup of the gag. By making Corbett the host, straight man, and target of ridicule, 7 Days reinforces an attitude of ridiculing those in positions of power by showing that those involved with the programme are willing to receive the critique that they use.

Jeremy Corbett thus functions to encourage viewers to identify and engage with the material that 7 Days disseminates, which is crucial for audience members to participate in the critical mode of identity that the programme uses (Bell 24; Davies 204). However, while Corbett has an important role in encouraging identification and therefore participation, the potential for creating identification is inbuilt to comedic spaces. Comedy is distinguished by its concern with representing and discussing everyday life as it is experienced by the middle and lower classes, as it is particularly rich for comedy, and subversive in its presentation (Neale and Krutnik 11). The appropriation of middle and lower class behaviours and values allow comics to subvert the norms of public decorum, which creates moments of comic surprise essential to comedic forms such as the comic insult, and resists norms of behaviour 
by problematising taste boundaries and social taboos (Neale and Krutnik 86). By framing issues in the terms of daily life, society is addressed at the micro level of control, placing issues of power and ideology in a framework that has relevancy to viewers (Silverstone 52). The potential that this comedic material creates for identification therefore serves a dual purpose, not only inviting audience debate and engagement, but creating further potential for subversion. This is because lower and middle class behaviours and values are often considered improper or frivolous, as taste and appropriate behaviour is defined by social elites (Bourdieu "Symbolic Power" 488; Neale and Krutnik 88). Lower class groups are more likely to be disempowered in society, and therefore comedy is ideally placed to encourage audience debate and discussion.

The transgression of behavioural norms is often taken to extreme because of the comedic setting. When the teams are introduced, the team captains even make fun of their own team members, and many other public figures are insulted throughout the programme, whether or not they have been in the news lately. Dai Henwood's comedic calling card is 'physical comedy', which he uses throughout 7 Days in a lewd manner. 7 Days condones these actions by giving Henwood a higher rank as team captain, which gives him the final say on team decisions and makes him one of the few recurring contributors. The lewdness of physical humour produces humour by speaking the unspeakable, subverting norms of decorum in a liberating manner (J. Palmer 12). These modes of expression not only work against the power relations of class structure, but also against the modes of discipline that seek to control the body by denaturalising it and silencing frank discussion (Bourdieu "Symbolic Power" 488; Foucault "Incitement" 491). The frank celebration of the usually tabooed body refuses the restrictions of decorum, and undermines the social world that demands a recognition of hierarchy through compliance with rules of politeness and deportment (Bourdieu "Symbolic Power" 489; J. Palmer 11).

The most obvious marker of 7 Days as a critical public sphere is the use of satire. Discourses of the public sphere and the politically motivated audience prioritise the need for access to and discussion of opposing views, and satire is an aggressive mode of comedic critique, seeking to expose hypocrisy, power relations, and even to pit different social norms against each other (Neale and Krutnik 19; Murdock 177). While the aggression of this critique is softened by it taking place in a humorous context, making fun of those in positions of authority empowers the speaker and their sympathetic listeners (Neale and Krutnik 19; Brown 134). Because of the inherent aggression of its critique, satiric modes of thinking provide an alternate viewpoint for audience members to consider, and by basing the 
programme on the week's news the alternate viewpoint presented by 7 Days is ensured relevancy and a public sphere role.

Both parody and satire are used by 7 Days, but despite their similarities they are very different comedic forms. Satire uses social conventions and is more insistently aggressive in tone, while parody is concerned with aesthetic conventions (Neale and Krutnik 19; Kercher 1). Parody is sometimes confused for satire because of satire's propensity for using parody to further satiric argument (Neale and Krutnik 20). Satire has greater potential to work as a site of comedic critique because of its focus on the social rather than the aesthetic, but parody can increase this critique by providing a means to further satiric communication. Parodic critique draws upon known aesthetic conventions in order to generate laughter, appropriating the characteristics of a system in order to attack its host from the inside (Neale and Krutnik 18; Brown 136). This works to subvert power relations, the parody revealing the constructed nature of norms that seek to appear natural, and framing them as ridiculous, thereby subordinating that which is parodied (Neale and Krutnik 19; Foucault "Two Lectures" 44). Watching the programme becomes part of the viewer's lived experience, an active practice of resistance with the potential to significantly impact upon a viewer's values and sense making processes (Brown 13; Foucault "Space, Power" 165).

The use of satire and promotion of a front man who embodies an idealised, if humorous, critical figure that can take critique, indicates the manner of engagement that 7 Days intends to promote. Television attempts to encourage its audience towards a particular mode of society through the events that are shown and the way they are framed (Bell 24). The use of parody and satire are intended to influence the way a viewer thinks in other contexts, and to promote a critical mode of understanding.

\section{Commercialism and National Identity}

Yet comedy's resistive and critical disposition is unpredictable, with both critique and the reclaiming of critique functioning in the same space. New Zealand television is quite commercial, and the economic consideration of audience size is quite influential on producers and a significant influence against effective critique (Bell 24). The small population of New Zealand means that the national audience is equivalent to niche audiences in larger countries, and therefore the framing of television content in national terms reaches for one of the few economically viable common grounds (S. Turner 95; Horrocks "Themes" 17). The discourse of ratings is the predominant method of judging a programme's success, and as such programmes often play on the New Zealand audience's susceptibility to depictions of New 
Zealand as 'special' in order to maximise audience numbers (Perry 17; Bell 22). The commercial pressure to include national signifiers is accentuated by New Zealand television including few comedies (Elliott 192). Despite comedic preference tending to vary greatly between individuals, as one of few local comedies 7 Days will be expected to appeal to all members of the audience, an excessive expectation for any comedy (Elliott 192; Neuwirth 1). Inclusion of national identifiers helps the programme to meet these expectations, but in prioritising New Zealand identity for commercial reason representations become guided by commercial imperatives, with cultural or political objectives a secondary priority (Farnsworth 334; Schirato and Webb 174).

These pressure result in 7 Days using an overabundance of positive representations of New Zealand national identity, as producers try to gather the largest possible audience and show them something that they will like (Bell 24). That national identity is framed in commercial terms is confirmed by the overt sponsorship of 7 Days by Tui Blond. A bottle of Tui Blond is used as the prize for the winning team, which they share while gloating at the loss of the other team. Tui Blond advertisements also start and end the screening of 7 Days, often using witticisms about New Zealand identity that reflect the humour style of 7 Days. After an episode of 7 Days finished with the game 'Let's Be Honest', the Tui advertisement that played immediately after the credits used the same 'Let's Be Honest' joke format, along with a slogan of 'The Honest Lager' ("New Zealand vs The World” 7 Days 59:07). Tui beer liberally deploys discourses of male New Zealand identity in their advertising, and so this sponsorship is highly indicative of the commercialised discourses of identity within 7 Days.

National identity is informed by the repetition of stock images, with the result being that New Zealand audiences are constantly shown who they are (Bell 29; S. Turner 95). Viewers do not necessarily unquestioningly accept these discourses, but the repeated images that viewers access through television are absorbed into the cultural landscape, becoming part of the networks of meaning and power relationships that have the potential to influence individuals (Horrocks "Themes" 6; Gupta "Blurred Boundaries" 228). Television provides a 'frame of reference', establishing a truth of national characteristics that members of a society can then construct their reality through (Horrocks "Themes" 6; S. Turner 95). While New Zealand news is heavily critiqued by 7 Days, and sometimes also the sub-identities within New Zealand identity, New Zealand nationality in itself is never subjected to sustained critique. Habermas prioritised a need for the public sphere to be free from state and commercial influences, and it is in this uncritical portrayal of New Zealand identity that the need is demonstrated (Silverstone 67; Briggs 5). By basing images of national identity in 
commercialised myth, the images are altered to reflect a flattering, positive identity to the audience. Viewers are invited to think of themselves as New Zealand subjects, and to be proud of this identity, which enables the unquestioning continuation of the nation state, and reinforces blind trust in existing capitalist power structures.

This avoidance of critical examination of New Zealand identity is quite problematic, as the continuous stream of images and discourse provided by television influences the way that viewers construct their conception of the nation, and their place within that nation (Horrocks "Themes" 6). The images provide audiences with a sense of community, repetitively drawing upon themes of nature, masculinity and sport, to generate a sense of uniqueness and recognition in the audience (Bell 24; Anderson 256). However, this same sense of community invites the viewer to monitor themselves and others in relation to what it means to be a 'New Zealander'. Images of national identity work to shape an individual's identity, in a form of non-governmental social power that aims to create a docile, productive workforce (Ransom 13). National identity is particularly relevant to the exercise of bio-power, as a coherent mass identity that groups subjects together and strengthens the state's position of power (Dreyfus and Rabinow 137). The circulation and reinforcement of certain images of identity makes the audience aware of what the norm is, and implicitly frames other modes of identity as abnormal (Schirato and Webb 133; Foucault "Interview" 283). Most subjects are receptive to images of what is normal and desirable, even actively seeking normalising templates (Schirato and Webb 187). National identity is therefore able to be usefully manipulated to ensure that subjects are committed to the continuation of the state. The uncritical reinforcement of national identity reinforces panopticon methods of disciplinary power, inviting viewers into a cycle of checking themselves and others against the norms that are regularly reiterated on programmes such as 7 Days (Schirato and Webb 147).

This is not to claim that the programme overtly and consistently promotes New Zealand identity. While critique of New Zealand identity on 7 Days is extremely uncommon, there is minor inclusion of critique of what it means to be a New Zealander. A subject's habitus is highly durable, and retains a commitment to the values of their field even when subjected to the strong force of economic imperatives (Webb et al. 195). Although the comedians are necessarily aware that they are in a commercial space and thus cannot go too far and alienate the audience, they are also unable to abandon their role in disturbing norms and performing critique. Critical myths of New Zealand sub-identities, such as Christchurch residents being racist, are drawn upon frequently ("Episode 6" 7 Days 13:24). However, an underlying tone of pride in New Zealand identity is used as a base for these lesser critiques of identity. The 
uncommon critique of sub-identities is safe because the audience is made aware that the comedians are 'really' proud New Zealanders.

7 Days therefore critiques New Zealand identity on a micro level that is conducive with the commercial environment, reinforcing the idea of the nation as natural, and something to be proud of nonetheless. This is particularly apparent when guest comedians are from other countries. While these international guest comedians sometimes attempt critiques of New Zealand identity, they are never as well received as the critiques that the regular New Zealand comedians use. During the discussion of a news story on mining, an Australian comedian commented that the mine was originally intended for Hamilton until planners realised it was "already a hole" ("New Zealand vs The World" 7 Days 05:21). This got a laugh, but the laughter was shorter than usual, and host Jeremy Corbett even commented that the comedian made a 'stab' ("New Zealand vs The World" 7 Days 05:24). Dai Henwood, a New Zealand comedian and a regular on the show, then joined the mocking of New Zealand mining ("New Zealand vs The World" 7 Days 06:12). This appeared to authorise the Australian comedian's comedy, as the audience laughed louder and longer at the following jokes made by both Henwood and the Australian comedian. The regular New Zealand comedians are established within the comedic bounds of not meaning what they say, while the international comedians are outsiders to both the context of 7 Days and the national space that is regularly delineated, and are therefore less safe in making such critiques.

Comedy's potential to contribute to the public sphere is not completely nullified by its ambiguity over issues such as national identity. While the avoidance of critique of national identity by the comedians on 7 Days does serve to reinforce bio-power and naturalise the nation state, it also serves to ensure that the programme works as an inclusive public sphere. A public sphere needs to at least gesture towards the inclusion of all members of the public, and a national identity is a base identity that will reach most of the viewers (Schirato and Webb 190; Gramsci 81). Although the avoidance of critique of the nationality is problematic, it is necessary in order to ensure a critique of national news and events that viewers will actively participate in. 7 Days ensures a broad participation in public sphere issues because of its ability to entertain, and promotes debate, both of which are essential for a democratic and politicised space (Horrocks "Themes" 17).

The commercial imperatives that underpin televised national representations also have some positive repercussions. News programmes are more highly rated in New Zealand than in any other country (Bell 26). Demand for local content was fuelled by deregulation and has therefore been focused on cheap and reliable forms of local programming, leaving news 
programming as one of the safest options due to its low costs and high ratings (Farnsworth 334). This lead a great deal of locally produced television to be conceived with news and information frameworks, with news, current affairs and sport accounting for approximately 80 per cent or more of local content at most times (Farnsworth 334; Lealand "Regulation" 217). Comedy, on the other hand, is a far riskier option for broadcasters, as audience response is notoriously difficult to predict (Horrocks "History" 23; Neuwirth 1).

By mixing news and comedy together and adopting many of the aesthetics of news, 7 Days becomes a less risky format than other comedies while still providing an important outlet for critique. The satiric methods of critique that the comedians utilise are aggressive and likely to unsettle the audience without the one safe space of proud national identity. By leaving one form of identity safe, the comedians increase the potential for effective critique of news events and power representatives.

\section{The Inherent Ambiguity of Comedy}

Politicians sometimes come on 7 Days as guests and subject themselves to ridicule in person, as part of the game 'Yes Minister'. In this game, the comedians ask a currently sitting Member of Parliament a series of increasingly offensive questions, in the hopes of distracting the Minister enough to answer a question with 'yes' or 'no', for which the team who asked the question gains a point. This would at first appear to be a continuation of the public sphere role that 7 Days takes on, framing politicians as disinclined to commit to a definite answer, and worthy of questioning and ridicule. The subversion of power relations that this game entails is further reinforced by a clear delineation in the construction of humour. The 7 Days comics create humour deliberately, thereby demonstrating wit, intelligence, and cultural capital (Neale and Krutnik 47). This inverts usual power relations, as the subject of humour is shown as unintentionally funny, and is thereby framed as uninformed or stupid (Neale and Krutnik 47). Indeed, the whole point of the game is to trick the Minister into certain answers, which happens often and is usually followed by the comedians cheering and the guest politician laughing in an uncomfortable manner. No matter what the comedians say, the politicians are unable to defend themselves, unless they are willing to open themselves to further criticism of being unable to take a joke (J. Palmer 201; Gilbert 10).

However, the game is not as critical as it may appear. A core principal of democracy is that the will of the people is what authorises those in power (Schirato et al. 118; Simons 183). Public figures therefore need to make themselves available to expressions of public opinion, in a performance of a check and balance function that is necessary for their power to be 
legitimised (Schirato et al. 119). Politicians thus appear on 7 Days and subject themselves to satire, in which their intelligence and ability to lead attacked, in an effort to authorise their position of power. The satire is further nullified by taking place within limits, as 'Yes Minister' avoids mention of any actual policy or political events. Indeed, each guest politician is barely critiqued during their appearance. Other Members of Parliament are insulted, political scandals mentioned, but the guest themselves is only mocked in the terms of the Yes Minister game. When Auckland Super City Mayoral hopeful Len Brown was on 7 Days he talked about the Vodafone Music Awards, was asked if he "got a lot of pussy" as Mayor, and sang some of Play That Funky Music White Boy ("Episode 2" 7 Days 45:0046:20). The appearance of Len Brown within a heavily satirical public sphere portrays him as a good sport, and his performance as a 'good humoured bloke' was enhanced by the personal subjects that he was permitted to focus upon. The combination of his good-humoured performance with an avoidance of any actual political issues nullifies the effects of any critique that slips through.

Further exacerbating the reinforcing of power in this game is the unequal access to 7 Days, as shown by the appearance of currently sitting politicians which reinforces the status quo and denies similar legitimating expression to political hopefuls. Even the appearance of Len Brown, contender for the position of Auckland Super City Mayor, reinforced existing politicians rather than giving a voice to those entering the field or who dissented. Len Brown was already the Mayor of Manukau City, and therefore well known in politics. Success in Len Brown's Mayoral candidacy would increase his power, rather than give him access to previously unattainable power. This limited access aptly demonstrates how television is not the disinterested space that it claims to be (Schirato et al. 120). Rather, mediated communication is inextricably imbricated in other cultural fields, in this case politics, and commonly also economics (Schirato et al. 120).

Despite the limited and conflicted critique, the appearance of power figures on 7 Days is still useful to the public sphere. By bringing Len Brown into the space of popular culture, a power elite is forced to engage with the public on the terms that 7 Days sets (Simons 172; Hall 367). Those who govern society use cultural capital and inaccessible linguistic styles to assert their difference and qualification to rule, which ensures that positions of power remain inaccessible to the majority of citizens (Simons 183; Kercher 194). While popular culture is responsible to commercial imperatives and laws of libel it is in no way bound to positive representations of the state (Hall 367). Power figures need to successfully appear within the field of popular culture in order to win popular consent, but the power figures who appear on 
7 Days are forced to speak and act in the terms of popular culture that is directly opposed to the cultural capital that they hold (Simons 173; Kercher 194). Despite the lack of critique, by even engaging with popular culture Len Brown enters a space that is directly opposed to the forms of capital that he holds, and that forces him to be personable and act the fool, a direct contradiction of the mannerisms that authorise his position of power.

This is made obvious after Len Brown's segment of 'Yes Minister is concluded and comedian Paul Ego laughs that Len Brown can't possibly win anymore ("Episode 2" 7 Days 47.30). The implication of this assertion is that Len Brown's successful navigation of popular culture has invalidated his credentials as potential Mayor. Popular culture is one of the few forms that engages viewers in a way that increases the likelihood of voter action, but while Len Brown's appearance on 7 Days successful because he appeared funny and personable, it required him to disinvest himself of the cultural capital that legitimates his position of power (Simons 183). In this risky undertaking Len Brown has no feedback that may guide his performance, due to television's break between producer and receiver (Simons 185). Entering the field of popular culture is thus a fraught endeavour.

The comedic field of 7 Days is thus shown to be an ambiguous and contested space. Ambiguity is another fundamental marker of comedy, and places a limit upon how effective a critique can be. Comedy's illogicality's have a degree of logic, the absurd statements often have a hidden meaning, and despite a tendency to emphasise the arbitrary nature of certain power relationships and meanings by taking them to their limit, unadulterated absurdity is avoided (Neale and Krutnik 82). Rather than unadulterated critique, comedy critiques within certain bounds, thus providing an outlet for the inevitable resistance and frustration generated by the exercise of power relationships (Foucault "Sex, Power" 167). The constraints of this outlet actually serve to enable the continuance of power systems without serious rebellion (J. Palmer 12). Balance and ambiguity is crucial for successful humour, as comedy that goes too far and unmasks its aggression will cease to be funny and attractive for viewers to engage with (Shershow 5; Gilbert 14). Yet it is also how the potential for subversion is contained.

The ambiguous nature of comedy is increased by its often ambiguous reception. Despite comedy functioning as an outlet for censored and repressed viewpoints, this function is not only permitted but institutionalised, thereby reducing the potential for audiences to critically consider the norms that it attacks (Neale and Krutnik 91; Brown 150; Lewis 2). Even satire, with its inherently aggressive critique, can be recouped by over performing it, which frames the discourse as absurd and not to be taken seriously (Elliott 184). Comedy thus becomes "the appropriate site for the inappropriate, the proper place for indecorum, the field in which the 
unlikely is likely to occur" (Neale and Krutnik 91). 7 Days signals this function from the very beginning of the programme. While the majority of the programme appears chaotically unplanned, with new games appearing often and no apparent set format, the opening sequence is ritualistically similar. Jeremy Corbett tells the audience that the show is 'Adults Only', and then tells the opening gag. This is followed by the title sequence, the visuals scrolling through images of public figures over the background of a calendar while discordant theme music plays. The audience is thus told all that they need to know in the first two minutes of the programme: that this is an adult space, in which news will be discussed in an offensive and irregular manner.

Comedy's ambiguous nature as a site of transgression that is recouped by its authorised nature explains a great deal about its social role. While the indecorum that comedy draws on has the potential to shock and offend it very rarely does, precisely because that is what comedy is expected to do (Elliott 184; Neale and Krutnik 92). Humour is framed by the expectation that the comedian does not mean what they say, as disturbing conventions is itself a convention in comedic communication (Neale and Krutnik 82; Berger 127). Comedy is created through a combination of utterances and the circumstances in which they are uttered, as comedic statements uttered outside of an acknowledged comedic space unmasks the aggression inherent to comedic utterances (Neale and Krutnik 64; Berger 127). Even the transgression of rules of decorum is not truly subversive, as the field of comedy can be seen as containing its own rules of decorum (Neale and Krutnik 91).

Comedy's norm transgression and indecorum works to undo cultural power structures, yet precisely because this forms the very basis of the comedic genre, comedy only has the potential for subversion and progression rather than fulfilling that function automatically (Neale and Krutnik 93). However, even though comedic attack is quickly nullified, it is still an important technique of resistance. Even when the potential for comedic critique appears unfulfilled, the comedic utterances have still marked the object of their humour with opposition, a refusal of the legitimacy of that object (J. Palmer 199). While it appears nonsensical for critique and the reclaiming of critique to exist in the same utterance, humour is indeed fundamentally contradictory, unable to be reduced to the severity of a serious statement or dismissed as ineffectual (J. Palmer 181; Davies 202). 


\section{Chapter 6: Discussion}

\section{The Inclusive Public Sphere}

7 Days, Campbell Live and Shortland Street all have significant potential as public sphere spaces due to their interpellation of the widest possible audience. They are on main free-to-air channels, requiring only a television set and an ability to understand English for viewers to engage with them. The programmes provide information about issues of concern to audience members, in a manner that promotes identification and prompts discussion. Each programme used these systems to create a public sphere that was relatable and inclusive for as many citizens to engage with as possible. However, although these televised public spheres had structural similarities, each framed public sphere issues and engaged the audience in discussion in ways that were shaped by the genre particular to that programme.

Campbell Live worked in the manner of a stereotypical public sphere because of the prioritisation of informative and rational performances of discourse (Dahlgren 419; Weber 70). The current affairs genre typically works to help viewers understand the events that have been in the news recently, increasing the depth of knowledge citizens have access to and thereby helping them participate in public life (Holland xiii; Corner and Pels 3). True to genre, Campbell Live only discussed three or four stories in half an hour, a typical format for current affairs programmes which enables them to include more background and context to the discussion of events (Anderson et al. 3). In the use of a rational method of engagement that draws upon scientific discourses, Campbell Live positions itself as a space outside of power relations that is devoted to critiquing power through truth (Danaher n. pag; Campbell 325).

John Campbell, the host of Campbell Live, plays a key role in cementing the programme as being outside of power. He positions himself as a friendly everyman that viewers can identify with, but that is also concerned with critique, adopting this role through a combination of a particular style of critique and his use of his bodily hexis, which he uses to signal the seriousness of segments and how the audience should engage with them. During hard news pieces and interviews of power representatives, John Campbell appears stern, critical, and attentive. In doing so he positions himself as a valid member of the journalistic field, adopting the recognisable bodily movements of a subject that is able to critically assess facts and not be fooled (Foucault "On Power" 105). His bodily hexis authorises him as part of the field of journalism, communicating his membership and capital within that field, and his 
authority to interpellate viewers to respond to news stories in a similar manner to himself (Brady and Schirato 8; Bourdieu "Symbolic Power" 480).

However, during soft news pieces John Campbell leans back in his chair and appears cheerful and relaxed, sometimes even talking about his children. John Campbell performs as a reliable representative of 'us' that will hold 'them' accountable. In order to reinforce himself as one of 'us' John Campbell must embody elements of his target audience in his soft news pieces, which he does by referencing his role as a father or sports fan (Campbell 317). As both hard and soft news pieces are included in each broadcast this changing performance enables John Campbell to authorise Campbell Live, by taking on the role of the ordinary citizen who happens to have a great deal of capital in the field of journalism. The audience is therefore invited to see John Campbell as being 'one of us', but to still take him seriously in his role as a critical journalist. This performance is typical of current affairs show hosts, who need to hold audience attention and demonstrate why they should become invested in the programme (Hartley 90). In doing so, John Campbell works as the anchor and mediator of the different stories that are discussed, the everyman that the audience can both identify with as part of 'us', and that can be relied upon to critique power and its representatives, this framing the programme as a critical space that welcomes ordinary people.

Although this performance could be derailed by recognition of his privileged position in the media landscape, John Campbell uses his role as host to position himself as responding to events, thereby concealing his role as a powerful gatekeeper in the dissemination of information and discussion. Campbell Live often shows John Campbell responding to news stories, narrating footage, or interviewing those in power, but he is rarely shown actually investigating and putting together stories himself. He is therefore positioned as responding to information and then critiquing the information that is available, a performance which reflects the method of engagement open to viewers of Campbell Live. The use of his bodily hexis when responding to hard news stories, taking on the position of rational, disinterested seriousness, has a great deal of cultural capital within the journalistic field and ensures that John Campbell's performance as everyman does not go too far (Brady and Schirato 11; Anderson et al. 5).

While news and current affairs are the genres traditionally associated with public sphere processes of political activity, the most watched programmes tend to be those that are considered entertainment (Murdock 178; Zoonen 110). These large audiences are an important foundation for public sphere activity, and although entertainment programmes are less obvious spaces of critique they are just as capable of providing information, rationalising 
this information into applicable knowledge, and facilitating and prompting debate (Simons 179; Murdock 178; Couldry et al. 23). Indeed, it is not just media output that is important to public sphere processes but the investment that it can cultivate in viewers, inviting active interaction with political ideas and events rather than simply allowing the passive reception of information (Dahlgren 413; Foucault "Sex, Power" 168). Alternative genres facilitate different discourses and manners of engagement that work to broaden the public sphere, including groups that are marginalised by the priority for rational, intellectual critique (Fraser 494).

7 Days is an entertaining space that promotes audience investment in critique through satirically critical discussions of news stories. The programme subjects the news of the past week to comic discussion, which often employs satire to aggressively critique the subjects of the news story. This prioritisation of comical critique works to undermine existing power relations, as comedy inherently relies on techniques of surprise that subvert norms and conventions by revealing their incongruities (Neale and Krutnik 83; Berger 127). The heavy use of satire also works to ensure the space is critical, as satire is an aggressively oppositional discourse that cultivates a disdainful attitude to those in positions of power (Neale and Krutnik 19). The prioritisation of laughter also disrupts dominant constructions of news as an important, yet uninteresting space (Brown 149). The comedic critique therefore combines with the current events base to guarantee that each episode will criticise power structures and their representatives (Neale and Krutnik 19).

The performance of host Jeremy Corbett has a similar authorising function for 7 Days as John Campbell performance does for Campbell Live. Indeed, because 7 Days is situated in the field of comedy Jeremy Corbett is able to embrace the role of everyman even more than John Campbell, as he can roll his eyes, talk candidly and use colloquial language to critique events (Reeves et al. 82). Because Corbett is the host of 7 Days rather than the main producer of comedic banter, he takes on the role of straight man in a comedic space; he is often shown reacting, laughing or looking shocked by what other comedians have said. In doing so, Jeremy Corbett is able to embody some of the public sphere values of detached evaluation in a relaxed manner of critique, remaining removed enough from the excesses of comedy that the audience can accept some comedic critique and still take him seriously (Reeves et al. 82; Bourdieu "Symbolic Power" 488). Corbett's bodily movements reinforce his critique by producing him as an authorised member of the comedic sphere, but one who is relatable and candid (Bourdieu "Symbolic Power" 480). The role of host allows Jeremy Corbett to simultaneously take up the positions of the everyman and the trustworthy critical figure. 
In utilising relatable hosts the material in both Campbell Live and 7 Days becomes more relevant to viewers, which in turn encourages audience discussion of the programme and critical thought on the subject matter (Silverstone 52). The particular framing of the hosts creates the potential for the audience to see themselves as citizens with a stake in the public sphere, a crucial foundation for active engagement (Dahlgren 422). The hosts not only invite viewers into the public sphere, but authorise the speech and information dissemination that takes place within it, communicating its social value (Bourdieu "Symbolic Power" 480; Bourdieu "Field of Power" 90). By authorising communication in this manner both hosts create the potential for the viewer to take on the values of critical speech (Brown 13; Gordon xvi). While the hosts use different techniques and styles that demarcate their particular genres, these styles work to produce the critical values of those generic fields as natural and authorised (Bourdieu "Symbolic Power" 487). 7 Days and Campbell Live create the potential for the programmes to effect viewers outside the initial broadcast through their use of hosts that are intended for the audience to both identify with and emulate.

Shortland Street differs from both of the other programmes in prioritising an emotioncentric discourse that is usually not considered appropriate for the public sphere (Geraghty "Study" 318). Shortland Street personalises issues through fictional narrative, showing social crises in practice. Emotional discourse is typical for soap opera, which domesticates public sphere issues by showing social concerns worked through in a fictional home setting (Casey et al. 86; Silverstone 68; Slade 32). The public sphere that soap opera constructs shows social concerns from an alternative viewpoint by prioritising discourses of personal, emotional, feminine and family (Dahlgren 419). These discourses work to particularly prioritise women, but also create a space for many subjectivities that are disadvantaged by the more traditional public spheres, creating resistance by modifying values of legitimacy to include discourses that allow participation by disenfranchised members of society (Dahlgren 425; Bignell 172; Foucault "Sex, Power" 168). Characters and storylines are used to entertain the audience while simultaneously addressing contemporary issues in a relatable manner, thereby stimulating resistive political discussion between audience members (Hobson 160).

In contrast to 7 Days and Campbell Live, Shortland Street authorises discussion by using a community that is designed to be familiar to the viewer, rather than a front person for the audience to identify with. Shortland Street's narrative is based on the community through the use of characters which portray families and friends in 'typical' jobs, and frequent the familiar settings of a local coffee shop, staff room, and bar (Casey et al. 225; Bignell 161; Bowles 122). As well as these commonplace settings and routines, everyday language and 
colloquialisms are used by the characters (Casey et al. 86). This community basis allows Shortland Street to reflect areas of current concern to the audience in an easily relatable manner by framing them within familiar routines of daily life (Hobson 139). These aspects construct the programme as inclusive and relatable by reinforcing Shortland Street as a familiar community based public space.

As part of ensuring that discussion is comprehendible and framed in terms that the encounters in daily life, prolonged talk is used as a dominant aspect of these emotion-centric narratives, using gossip is used to bring complex issues to the level of the everyday (Hobson 22; Fiske 80). Soap's long form narrative means that talk and gossip over a single issue can take place over a protracted length of time, which creates a rare time opportunity in the television landscape for complex examination social issues in a manner that is inclusive and relatable (Hobson 134; Slade 32). The large cast of recurring characters allows Shortland Street to frame contentious issues within a certain level of familiarity and for a range of contesting viewpoints to be discussed, thereby setting discourses of truth in opposition to each other and allowing examination of their construction and contradictions (Hobson 141; Foucault "Two Lectures" 31). This prioritisation of dissenting speech is significant, as power relations can not only be instigated and confirmed through the use of discourse, but also resisted (Foucault "Two Lectures" 31; Foucault "Sex, Power" 168). By discussing social issues in familiar settings with familiar discourses, Shortland Street creates a relevant and accessible platform for the discussion of problems (Briggs 8).

7 Days, Shortland Street, and Campbell Live actively construct themselves as outlets of resistance, all three working to create a relationship with their audience that invites engagement with public sphere discussion. While the programmes use genre specific discourses to produce critique, each strives to attain a relationship of familiarity and representation that is inclusive of the ordinary citizen. Each space is always resistive at the minimum level of declaring refusal, and has moments of further resistance which involve active creations of meaning and changing the situation that power is operating within (Foucault "Sex, Power" 167; J. Palmer 199). Power relations are negotiated through the resistance that this encourages, obliging those in positions of power to acknowledge the opposition in some manner (Foucault "Sex, Power" 167). While the discourses that are used are different, each programme deploys them in a manner that strives to include as many citizens as possible. 


\section{The Representative Public Sphere}

The inclusivity of Campbell Live, Shortland Street and 7 Days works to produce the programmes as authorised representatives of different, politically motivated audiences. Each programme then further produces itself as contesting power for the audience members that it represents. Once each programme has constructed itself as representative each then lays claim, either explicitly or implicitly, to achieving something for this audience.

Campbell Live does this by providing the audience with access to the public sphere, allowing them to actively participate. By informing citizens of political events, news media gives them the tools to resist disciplinary influences, undoing the subtle processes of subjectivity shaping by drawing attention to power systems and representatives and giving citizens the opportunity to participate in, and be knowledgeable of, democratic systems (Schirato et al. 52; Allaun 12). However, the programme not only provides information about events, but also works as an example of critical thought, representing critical discourses to the audience that citizens can then take up and use. Viewers are addressed as concerned citizens that will take action, as the programme actively prompts viewers to participate by displaying an email address for viewer feedback along the bottom of the screen three to four times in each half hour screening. This not only encourages a critical mindset, but promotes forms of resistance which work change the fields that power can be exercised through (Foucault "Sex, Power" 168). The inclusion of audience feedback through email interpellates viewers as politically active citizens, allowing them to critique both the subjects of stories and the stories themselves through this function. Audience members are thereby prompted to take up the modes of critique that Campbell Live promotes.

These plentiful opportunities for audience involvement allows Campbell Live to retain the public sphere principle of the 'universality of availability' and lessen the inherent potential for traditional news sources to function as a conduit of information (Thussu 24; Corner and Pels 3; Anderson et al. 9). Even if audience members do no more than email the show, Campbell Live has prompted participation in public sphere discussion in an accessible medium. By frequently displaying and talking about the emails received in each broadcast, Campbell Live ensures that differences of opinion are heard, thereby lessening the homogeneity and one-way manner of communication that afflicts mass media (Thussu 24). In doing so, Campbell Live moves past being a simple method of transition to an active public sphere conversation between citizens (Anderson et al. xix).

This is possible because of Campbell Live's position as an overtly political public sphere, with John Campbell as a host that is not only authorised to interpellate viewers as politically 
motivated citizens but also to speak to power representatives on behalf of 'the people'. While viewer opinion is included in the form of emails, John Campbell avoids expressing anything that could be perceived as his own opinion. Instead he asks questions in a concerned manner, presents news stories prepared by other journalists, and reads aloud viewer opinion that he barely reacts to. This ensures a performance of removed critique, exemplifying the manner of engagement that Campbell Live promotes through the use of this detached by the relatable host.

The critical speech that this encourages is a central technique of public sphere engagement (Dahlgren 430; Foucault "Sex, Power" 168). In disseminating critique Campbell Live lays claim to the powerful discourse of truth as a method of active resistance (Foucault "10 March" 372; Foucault "Two Lectures" 32). This method of truthful speech aims to foster resistance by problematising taken for granted beliefs and activities, the use of these discourses actively producing acts of power or resistance (Foucault "10 March" 372; Sheridan 128). By participating in critical discourse, subjects are encouraged to adopt distrust of power representatives as a normalised state, using critical speech as a power discourse that can negate power exercised upon them or enable them to exercise power over others (Hartley 1; Foucault "Two Lectures" 31; Butler 499).

Although the prioritisation of humour may make 7 Days seem very different from the rational space of Campbell Live, the two programmes make remarkably similar claims on behalf of their audience. Both promote suspicion of power figures, use of critical thought, and use of a role model host who is relatable but still highly critical, to create the potential for citizen's to take on critical discourses. By utilising satire and promoting Jeremy Corbett as an idealised yet humorous critical figure, 7 Days signals to the audience not only how they are intended to engage with the programme, but the critical methods of thought that it favours. While the rational critique that Campbell Live prioritises is an extremely important contribution to public discourses, it is by no means the only method of enacting critique or inviting audience members to active modes of resistance. The traditional preference for rational critique that is produced by informed participants serves to marginalise disempowered groups who lack the required education to access these discourses (Slade 193). 7 Days provides an opportunity for participation in the public sphere by disempowered members of society, by utilising humour and colloquial speech patterns that most audience members will be familiar with (Slade 185; Corner and Pels 3).

While the use of the host is important, 7 Days is a programme that is particularly disposed to critique on behalf of it viewers because of genre. Comedy fosters subversion through its 
use of comic surprise that forces subjects to rethink assumptions, and transgresses rules of decorum by using techniques such as the comic insult (Neale and Krutnik 88; Brown 150). In the transgression of norms systems of power are denaturalised, subverted so that formerly closed areas of speech and meaning are demystified (Brown 150; Foucault "Two Lectures" 31). Because subversion of rules and norms are carried out within the realm of comedy, a site where comedians are powerful, witty, and intelligent, critical subversion of norms is framed positively (Neale and Krutnik 47).

This promotion of critical modes of thought creates the opportunity for subjects to resist by taking on these values and naturalising them into their cultural history (Danaher n. pag.; Schirato et al. 56). If subjects absorb these critical values into their habitus, the resulting disposition to detached, critical thought means that subjects will recognise subtle forms of disciplining and norm creation that they had previously not been aware of (Danaher n. pag.). By laughing at power representatives in news stories the comedians on 7 Days contribute not only to creating a priority for critique, but to produce humorous and subversive discourses that viewer's can take up. The comedians use 7 Days as a public platform to say the things that cannot be said, and in doing so, unmask possibilities of speech for audience member's (Brown 16).

Despite sharing the characteristic of a prioritisation of alternate viewpoints with 7 Days, the claims that Shortland Street makes for its audience are very different from both of the other programmes, as are its methods of achieving these claims. The public sphere is typically thought of as a space of rational discussion, but soap opera uses emotionally based discussion to engage the audience in current hot topics, prioritises female perspectives and discourses because of its use of the domestic and personal realms as the setting for the discussion of societal issues (Geraghty "Study" 311; McCarthy "Studying" 48; Casey et al. 206). This method of communication has the potential to produce empathy in audience members, which is crucial to understanding the perspectives of disempowered members of society (Slade 185). Both Campbell Live and 7 Days use white male hosts, and the majority of the comedians who appear on 7 Days are also male. Shortland Street, on the other hand, is true to its genre in featuring a diverse range of women, many of whom are strong, lead characters. An ensemble cast is used to create a feminine space of discussion and 'working through,' ensuring the presence of feminine points of view and modes of discussion that are usually considered 'inappropriate' for the public sphere (Casey et al. 226; Geraghty "Study" 315; Geraghty Women 196; Brown 1). Shortland Street is thus a space that works to 
represent a wider swathe of society, thereby empowering members of the population that are usually marginalised.

The representative, emotional basis of Shortland Street's public sphere is important to levelling power relations, as the rational discourses that are traditionally associated with the public sphere are usually only accessible to those already in powerful positions (Slade 193). Domestic language codes, however, are understandable both to those in positions of power and those who are disempowered (Slade 193). Promoting perspectives of the domestic, personal, and feminine, thus disseminates patterns of discourse that are usually suppressed from public sphere discussion (Brown 33). In doing so, meanings and values that are also usually ignored are articulated in the public setting of television narrative (Brown 33; Briggs 5). This gives previously disempowered groups the opportunity to discuss issues in their own terms, thereby resisting methods of control that seek to keep them mutely subjugated (Brown 19; Silverstone 65).

By prioritising discourses of community and feminine perspectives soap opera works to construct a cohesive and politically engaged female audience that poses a threat to traditionally masculine power systems (Brown 19). A predominantly female cast utilise feminine methods of communication and points of view, thereby challenging prevailing ideals of what can be said and how (Brown 13; Seiter and Wilson 136). This provides alternative discourses for political discussion to be directed through, allowing audiences to conceive of and verbalise issues in a manner that works against dominant masculine culture (G. Turner The Demotic Turn 8; Brown 16; Briggs 8). By airing Shortland Street in prime time the challenge that Shortland Street represents is brought into mainstream culture (Dunleavy 41). Public broadcast of issues framed in these domestic terms enables the use of domestic terminology in other public settings by ensuring that these discourses are not only available for viewers to draw upon, but that they become naturalised into daily life and thereby reinforced as valid (Brown 8; Slade 194).

Even if Shortland Street's role as a promoter of disempowered discourses and values was overlooked, it is a particularly valuable public sphere because of its ability to foster discussion between viewers (Casey et al. 224; Geraghty "Study" 319). It achieves this through a use of controversial storylines in a relatable, talk focused setting, the controversial storylines prompting reaction and the talk focused narrative naturalising viewer discussion during or after the programme. The personalising of social issues allows the audience to follow a character's progression through a problem and the range of decisions that they face in dealing with it (Hobson 134). Enmeshing a familiar character within social issues 
universalises problems and invites viewer identification, which increases audience confidence to engage in discussion on the topic (Hobson 29; Casey et al. 224). This discussion leads to opinion formation that is crucial for citizens to engage in other areas of politics (Dahlgren 420).

All three of these programmes produce themselves as spaces which work to produce active resistance of the exercise of power, and these localised struggles impact upon the entire network of power relations (Sheridan 139). The attractiveness of the programmes, combined with the prioritisation of frank communication from diverse viewpoints, provides a platform for dissent. These critiques are not so much attacks upon individuals or institutions, but of the forms of power that they exercise (Foucault "Subject and Power" 331). 7 Days, Campbell Live, and Shortland Street not only undertake the reframing of the discourses of truth that achieve these power relations, but to attract citizens to their respective spheres of critique. Although public sphere theory often assumes that if access to a public sphere is given citizens will eagerly participate, it is often the case that citizens need to be attracted to a sphere in order to engage with it (Dahlgren 413; Couldry et al. 3). Even the most eloquent critique is of no use to citizens or the public sphere if it has no viewers (Couldry et al. 3). Critical objectives are therefore balanced with entertainment, in the form of soft news, humour, or fictional narrative, which combines to create a public sphere space which audience members can become invested in and engage with. In the interpellation of viewers as actively invested in these spaces of active critique, resistance is cultivated by creating multiple opportunities for viewers to take up critique and resistance as a practice (Foucault "Space, Power" 165).

\section{The Contested Public Sphere}

While all three programmes have significant public sphere functions that cannot be disregarded, there are also significant influences that hinder the public sphere role of each programme. All three sites were highly ambiguous, conflicted spaces, resisting norms through critique at some moments and contradicting this critique at other moments. The ability of the televised New Zealand public sphere to promote critique and active resistance while never having the ability to completely step out of power systems and avoid reproducing dominant ideologies aptly demonstrated the shifting and unstable nature of power relationships (Crofts 271; Foucault "Sex, Power" 167).

A particularly salient impediment to public sphere critique and discussion in all three programmes is the necessity for them to perform commercially and attract big enough audiences to satisfy advertisers (Holland xvi; Thussu 15). Commercial objectives are difficult 
to reconcile with news values of detached, critical thinking, yet even the traditional public sphere provided by Campbell Live acknowledged commercial interests. Although news and current affairs often have strong ratings, they are still under a great deal of pressure to perform commercially as they are the genre with the most potential to capture an audience for the evening (Bell 25).

Campbell Live acknowledged commercial imperatives through its inclusion of soft news pieces, stories of human interest, crime or celebrity that used uncritical discourses and favoured style over analysis, yet have the potential to draw higher ratings (Holland xvii; Thussu 15; Corner and Pels 2). The soft news segments involved very little critical thinking, and thereby worked to reinforce norms and naturalise certain habits of thinking (Brady and Schirato 8; Foucault "Two Lectures" 44). As well as these sections being structured in an uncritical manner, host John Campbell used a relaxed bodily hexis during these pieces, which signalled to the audience that they also needn't engage with the soft news pieces in a critical manner. Despite critiquing the norms of public life, overt power structures, and authority figures through hard news stories, norms of personal life were disseminated in soft news stories without critique, reinforcing them by default.

While Campbell Live's negation of critique through soft news may seem inconsequential, the personal focus of these stories has a great deal of potential to impact upon the public realm. In focusing upon the personal realm, soft news stories disseminate norms of behaviour that give the audience the tools to use against themselves. Uncritical discourses circulated by television draw upon pre-existing myths and representations of identity, reinforcing certain characteristics of being particular to certain identity groupings and other manifestations of identity as abnormal (Bell 23; Foucault "Interview" 283; Schirato and Webb 148). Because of the time constraints that television faces, these become simplified images of identity, allowing identities to be referenced quickly and in a way that viewers will recognise (Bell 23; Webb et al. 188). These simplified images reinforce the pre-existing concept of what is normal and desirable, contributing to the system of representations that produce identity (Schirato and Webb 148; Foucault "Two Lectures" 36). These norms carry over into discussion of public affairs, producing values and behaviours that underlie debate (Foucault "Interview" 283).

The audience has little opportunity to refute these simplified and uncritical representations, as despite initially being invented as a method of two-way communication, television is now a centralised method of broadcasting messages to audiences in their homes (Neale and Krutnik 176; Perry 37; Hall 370). Disempowered social groups are unable to directly 
influence these commercial pressures, and thus are vulnerable to having their participation marginalised or ignored completely (Fraser 496). Indeed, a 'free' commercial press usually only frees citizens to consume the opinions of those with access to the capital needed to produce mass cultural texts (Hall 370). Leading subjects to self-surveillance in regards to norms of the personal undeniably impacts upon public political life, as it reinforces norms of certain fields of power (Schirato et al. 52).

However, if conflicted programmes such as Campbell Live were lost from the television landscape the hard news critique that it provides would also be lost. Indeed, inclusion of soft news stories serves public sphere imperatives as well as commercial. The public sphere needs to be inclusive for as many citizens as possible, a requirement that matches well with the commercial imperative for large audiences (Anderson et al. 5; Simons 181). Commercial imperatives ensure that Campbell Live attempts to appeal to a broad audience, and thus function as an inclusive space that many individuals will be drawn to (Holland xvii). A programme with overly highbrow aspirations will, by necessity, not be inclusive for a mass audience. Viewers who are excluded by highbrow programmes are likely to be those who are already associated with low culture and thereby disenfranchised subordinate groups most in need of a space for discussion and critique, while elite audiences are smaller in number but wield more power in society (Anderson et al. 7; Hall 370).

Soft news pieces not only retain viewers who would not usually be interested in hard news pieces, but attract viewers who could become overwhelmed by unadulterated hard news. Viewers are apt to becoming cynical and disengaged from the public sphere if they are overwhelmed by a plethora of bad news stories, the confrontational and aggressive style of Campbell Live during hard news stories requiring full critical attention and reinforcing a pessimistic world view by challenging the audience (Anderson et al. 4; Crofts 269). By combining difficult hard news pieces with light relief, Campbell Live prevents viewers from disengaging from public sphere issues, and frames the public sphere as one that is not too overwhelming to engage with (Anderson et al. xxi). The less confrontational style of soft news stories invites viewer engagement and emotional investment, ensuring that the audience is invested in the programme when confronting hard news items are broadcast, thereby retaining a politically engaged audience (Anderson et al. 7). Having this appeal ensures that Campbell Live not only survives commercially, but that the programme is inclusive for as many viewers as possible, something that is important for a democratic public sphere (Thussu 24; Anderson et al. xxi). 
7 Days is a correspondingly conflicted and ambiguous sphere, with commercial imperatives preventing excesses of aggressive satirical critique. The programme is screened at $9.30 \mathrm{pm}$, a time which signals to the audience that it is more adult fare. If audience members were in doubt of this, host Jeremy Corbett begins every show by saying that the programme is 'adults only' in the first few seconds of broadcast. This demarcation of the space means that the audience will engage with it differently, expecting the programme to shock them. Precisely because the programme is then expected to shock and subvert norms, it is unlikely to do so in a significant manner. The programme is thus able to be sponsored by Tui Blond, a similarly 'adult' drink that nonetheless does not want to offend potential customers. The schedule placement and sponsored nature of 7 Days lessens the impact of its critique, altering audience expectations and the level of satire that the comedians can attain.

Commercial values work upon Shortland Street in a similar manner to Campbell Live, but as soap already prioritises entertainment and the personal sphere the most noticeable outcome is the widening of Shortland Street to be a more inclusive space. Although soap is traditionally a feminine space that prioritises a female viewpoint, commercial imperatives also encourage it to include other viewpoints, a wide variety of identities and values being portrayed through the ensemble cast (Hobson 142). In doing so, Shortland Street avoids alienating viewers and ensures inclusive and comprehensive debate, thereby becoming a more inclusive public space. In prioritising a feminine viewpoint and discourses but retaining lesser inclusion of a wide variety of subjectivities, the feminine world view that is prioritised is able to become naturalised into the cultural histories of a wider audience.

While commercial imperatives do not negatively influence Shortland Streets's public sphere role, some genre characteristics do. Soap's technique of emotionally based presentation of current issues has been shown to significantly involve audiences, prompting active discussion between citizens and investment in the public sphere (Geraghty "Study" 311; Casey et al. 224). However, although soap opera adeptly works through issues of the personal and emotional, soap's overly dramatic style hampers its public sphere role by problematising the addressed issues, which frames them as requiring a 'solution' (Foucault "On Power" 106). While the inclusion of social issues in Shortland Street is useful to the public sphere, the prioritisation of emotional discourse leads to an initial hysteria in character's discourse, which reinforces the highlighted issue as abnormal, potentially even a sickness, and in need of rectifying (Foucault "Interview" 283).

This was at first the case with the inclusion of lesbian characters in Shortland Street, with a $2009 \mathrm{PhD}$ thesis finding the relationship between Maia and Jay in a constant state of 
instability, and dealt with quite superficially (Hopkins 140). Soap is particularly disposed to reinforcing normative values in this manner because it relies on the pleasure of the familiar, and requires crisis in order to propel the narrative (Schirato and Webb 190). Although this dramatic method engages audience interest and creates investment in storylines, it does not contribute to a fuller understanding of problems that lesbian women face, and reinforces lesbian identity as a problem in the first instance (Hobson 160). A common problem for soap is thus the ease with which it slips into reinforcing dominant norms through this combination of crises and familiar values. In problematising identity it is made vulnerable to exercises of power that seek to 'solve' it (Foucault "On Power" 106).

However, soap opera's long form narrative means that it is able to respond to criticism and to improve representations. Although Shortland Street initially problematised lesbian identity through Maia and Jay's relationship, Maia's current relationship with Nicole is dealt with in a manner much more similar to the heterosexual couples on Shortland Street. Although Nicole and Maia still have problems due to the soap genre's need for domestic problems to work through, the couple no longer face endless problems specific to their sexuality, and they are also shown in moments of quiet domesticity that normalise their relationship. This demonstrates that Shortland Street has the potential to make the unfamiliar understandable, by framing social issues and identities within familiar characters and settings and allowing long-term exploration (Hobson 142; Geraghty Women 131). The programme conducts this exploration on a platform of high viewership, as Shortland Street is a typically high rating soap opera and one of the longest running and most successful programmes on New Zealand television (Hobson 142; Dahlgren 420; Tulloch 151). As long as issues and characters are included in a long term manner soap's extended narrative will reach a stage of exploration without problematising, at which point soap can both engage with and entertain their audience, and in the long term potentially erode norms and stereotypes (Hobson 160).

Similarly to Shortland Street, the majority of 7 Days' conflicted public sphere function is actually due to the ambiguous nature of comedy itself. Humour is created through a balance of logic and illogicality, humorous plays of meaning that court ambiguity by necessity (Neale and Krutnik 82; J. Palmer 18; Shershow 3). This then combines with humour's role as a condoned space of subversion, as although comedy serves to critique it can be seen as "a kind of licensed release that serves to distract people from their oppression and is thus not resistive at all" (Brown 150). Because comedy is expected to shock and offend it rarely does, as audiences understand that comedians do not sincerely mean what they say which is what enables offensive statements to generate laughter (Berger 127; Neale and Krutnik 82; Elliott 
184). Comedy therefore has the potential for subversion of norms but subversion cannot be guaranteed, as it depends on how the comedy is deployed and the audience reaction to it (Neale and Krutnik 93; Brown 150).

However, it is the ambiguity of the programmes that enables them to be broadcast through the mass medium of television. In the mass broadcasting of popular culture they are exposed to power relations that attempt to recolonise the texts (Simons 181). This inherent conflict of medium means that televised popular culture is a site of constant struggle between the popular and the dominant, demonstrating the inevitable circulation of power in which individuals constantly move between exercising power and having power exercised over them (Simons 181; Foucault "Two Lectures" 36). Yet even if these power relations permeate the texts they can only nullify critique rather than eliminate it, and it is this conflicted nature of critique which enables its continuing broadcast (Gauntlett 131; J. Palmer 12; Perry 17). While there are moments in which particular meanings and discourses gain ascendancy victory is never final, and television is thus a space of fundamentally contested meanings (Simons 181; J. Palmer 199).

Indeed, as an inherently ambiguous and contested space the televised public sphere demonstrates the instability of the network of power relations and discourses (Simons 182; Foucault "Two Lectures" 36). Viewers may not be entirely liberated by their media consumption but they are also not wholly dominated, as power is unable to be exercised in totality (Simons 182; Foucault "Space, Power" 165). Rather than passively absorbing the broadcast positions viewers are offered a myriad of perspectives and discourses that they are encouraged to actively criticise, take up, or reject, thereby becoming mediums of power rather than passive subjects of it (Foucault "Two Lectures" 36; Foucault "Subject and Power" 342). Viewers are able to access the programmes as sites of opportunity which circulate discourses of competing power positions and active resistance to them, rather than purely as sites for the exercise or resistance of power (Foucault "Subject and Power" 342; Nealon 97).

\section{The Role of the Nation}

All three spaces are thus ambiguous, working as sites of inclusive critique in some moments, and closing down meanings and disseminating norms in other moments. The most overt example of this conflict in all three programmes is their use of national identity. While contemporary subjects tend to consider themselves part of diverse identity groupings, national identity is one of the most easily universalised identity groupings, as most subjects imagine themselves to have a national identity (Anderson 256; Gramsci 81). This forms a 
common ground between themselves and the many other members of the nation (Anderson 256). The national discourses were used as one site of safety, a meta-identity which then allowed further critique and activism in other areas.

The dissemination and consumption of mass media texts play an important role in the imagining of nationhood, the texts signalling certain categories of identity (Schirato et al. 57; Gupta "Imagining Nations" 269). Public sphere claims of critique are limited by the necessity of not challenging every norm that a subject has absorbed into their habitus, with critique instead taking place within familiar images which create a sense of community and provide respite from the work involved with stepping outside of norms to critique power relations (Schirato et al. 56; Campbell 326; Bell 24). As critique can be tolerated by citizens when they take place within an underlying continuity of meaning, the communal culture of the nation was used by all three programmes to provide this underlying meta-identity (Schirato et al. 56). A public sphere that is inclusive and has an area of safety that viewers can rely upon enables greater viewer participation (Horrocks "Themes" 17; Couldry et al. 3). Local content rates very well in New Zealand, and while this may have commercial implications, it also ensures material that is relevant to New Zealand citizens and that they are likely to engage with it (Bell 26; Farnsworth 334). The use of New Zealand identity as an uncritiqued meta-identity base for each programme allows the interpellation of a diverse and invested audience.

Campbell Live embeds national identity as a safe meta-field into its structure, ensuring it is signalled in each broadcast by using a graphic of the New Zealand islands with the Campbell Live title laid over the top for both the title and credits sequences. The use of this image to open and close the programme gives the audience a very literal signal that the critique will take place within a nationally demarcated space. News is particularly disposed to such signalling and dissemination of national identity, as it is common practice for stories to be identified by region and for national news to be treated as more important and interesting (Bell 22). However by including national identity in the structure of the programme, Campbell Live's story segments are framed as distinct events that take place in the wider cultural field of nationalism. This identity is then reinforced by John Campbell's use of national discourse and displays of national pride.

Shortland Street similarly structures national images into its format rather than relying upon explicitly referencing it. Locating shots are used three to four times in each thirty minute episode, each time showing an attractive view of Auckland city. This constantly reminds the viewer that the events are set in Auckland city and plays on a desire to believe that New Zealand is superior and unique, by using familiar shots of pleasant weather, shiny 
high-rise buildings amid a leafy landscape and yachts on a harbour to produce recognition and reiterate common myths of naturally picturesque New Zealandness (Bell 24). These familiar themes are reworked to construct Shortland Street as a familiar space, while simultaneously reinforcing Auckland, and New Zealand in general, as a special place.

Even the simple visual methods of communication used by Shortland Street and Campbell Live tell viewers who they are, and invite them in to the community of national citizens (Bell 21). Indeed, images are one of the fastest and most effective methods of communication, requiring no specialised literacy to communicate the communal identities television seeks to cut across the multiple imagined communities that contemporary subjects belong to (Simons 179; Murdock 176). The dissemination of 'national culture' gives citizens evidence of both shared values and a common cultural history that reinforces the imagining of a common national identity (Schirato et al. 57; S. Turner 91; Gupta "Imagining Nations" 271). The images disseminate pre-existing national myths which reinforce existing categories of identity and their requirements (Schirato et al. 57; Horrocks "Themes" 5; Crofts 271). These myths are then repeated across different cultural texts, as demonstrated by Shortland Street and Campbell Live having a similar reliance upon recognisable visual images to connote national identity in an unobtrusive manner.

In repeating these myths and images of identity signifiers and their meanings are normalised and become recognised categories of identity, even if the audience has not experienced them outside of these mediated representations (Brady and Schirato 12; $\mathrm{S}$. Turner 91). While this form of subjectivity production could be disrupted by refusing to respond, there are some subject positions that are extremely difficult to refute, proud national citizenry being one of them. Schirato et al. use the example of the Uncle Sam imagery: "Uncle Sam has stated that he wants 'you'; he would only want good citizens, therefore you are a good citizen ... You do not have to believe - he believes for you" (54). When an individual is interpellated as a good citizen, who cares about their country and is patriotic, it is hard to respond in any manner but compliance (Schirato et al. 54).

The repetition of normalised images that may have no bearing on experience is particularly apparent in the construction of Shortland Street's community. Despite being situated in Auckland, Shortland Street draws upon a national theme of nostalgia for the 'small town' community that New Zealand viewers are highly receptive to (Dunleavy 46). It achieves this through the use of conservative yet politically correct values and a high value on gossip and knowing what other members of the community are up to (Dunleavy 46). This construction is successful not because it resonates with viewer experience, but because it is a 
familiar discourse that is repeatedly circulated (Dunleavy 48). Viewers are invited to feel part of this community, as Shortland Street is careful to maintain a cast that reflects the genders, demographic and ethnic profile of its audience, which also works to make familiar representations of other members of the nation that an audience may never meet (Dunleavy 46; Anderson 256). Viewers are likely to find this interpellation difficult to refuse not only because of the rural, small-town ideology that is at the heart of most constructions of New Zealand identity, but because of their privileged position within it (Dunleavy 48).

This usage of national identity as a common ground that is safe from critique is problematic, as patriotism is a main source of norms that of seek to control the population and perpetuate the state (Schirato et al. 57). National identity is not only a form of identity that most citizens will relate to in a sense of meta-identity, but that is one of the most powerful and established forms of assembling citizens to enable the continuance of democratic government (Murdock 176; Anderson 254). The simplified images of television work to reinforce existing power structures, as the simplest images are often those which strengthen pre-existing myths and representations of identity, even if viewers have no experience of those myths outside of mediated representation (Bell 23; Schirato and Webb 148; Anderson 256). Visual culture is ideally placed to manipulate emotion, and thus the promotion of unquestioning patriotism has the potential to discipline the population into accepting dominant norms of national identity, and monitoring themselves accordingly (Schirato et al. 57; Thussu 20).

That national identity serves as the meta-identity for all three programmes is strongly related to the specific production pressures of the New Zealand television landscape. While the vast majority of public media institutions worldwide aim to promote national identity, discourses of national identity are particularly prevalent in the New Zealand television landscape, even in the privately owned channels (Slade 192; S. Turner 95). New Zealand's small size means that the entire national audience is equivalent to a niche audience in England or America, thereby leaving little room for other identities to serve as a commercially viable programme base (S. Turner 93; Horrocks "Themes" 7). New Zealand also has some of the lowest levels of locally produced programming in the world, which means that locally produced programmes have a point of differentiation which constructs the programme as particularly relevant, and therefore attracts audience members (Horrocks "Themes" 10; Horrocks "Construction Site" 277). National identity is used as the safe metaculture for all three programmes because it is one of the only commercially viable forms of common culture in the New Zealand broadcasting environment (Horrocks "Themes" 10). 
However, the commercial influences on national identity have strong implications for the imagined communities that viewers are invited to join, and increase problematic elements of this meta-identity (Murdock 176). Commercial conditions of production mean that the national representations are often more strongly guided by commercial requirements for a flattered, positive audience, rather than a prioritisation of political or cultural values of critique (Farnsworth 334; Schirato and Webb 174; Bell 24). Viewers need to not only recognise signifiers of national identity, but want to join the represented community (Bell 24). Representations are therefore overwhelmingly positive, featuring egalitarian citizens with a love for the beautiful outdoors that New Zealand offers, and a friendly loyalty to other members of their national community (Dunleavy 48; Bell 23). This national loyalty is no doubt hoped to rub off on the products that associate themselves with the discourse.

The commercialisation of national identity is strongly visible in both Campbell Live and 7 Days. Both programmes start and end with images of their principle sponsor, Mazda and Tui Blond respectively. Their sponsors are then further included in the moments before breaks for advertising, the logo appearing next to the titles for upcoming stories Campbell Live, and by Tui Blond working as the prize for the winning team on 7 Days who share the beer while being congratulated. Both advertisers will welcome their product's association with the programmes, and will require that the programme has an image that is conducive with their brand image. In the inclusion of a main sponsor into the programmes themselves, Campbell Live and 7 Days reveal the commercial pressures that they operate under. The interpellation of viewers as concerned citizens within a nationally demarcated public sphere is difficult to refuse, but to respond under these conditions is to allow companies to tap in to this interpellation with commercial messages. Thus the extensively disseminated common culture of national identity is strongly imbricated within capitalist, commercial ideologies.

Commercial objectives also influence programmes through the prioritising of ratings. Despite comedic taste being a personal preference specific to individuals, the low levels of local comedic programming put a great deal of pressure on programmes such as 7 Days to appeal to the widest demographic, and as such 7 Days uses national signifiers to broaden the audience base as much as possible (Elliott 192). Light critique is made safe by focusing on sub-identities and the clear communication that even the comedians on 7 Days were proud New Zealanders 'really'. The programme explicitly communicates this in the 'New Zealand versus The World' special episode. This one hour episode started the new season of 7 Days, and used recurring New Zealand guest comics for Team One and international comics for Team Two. When host Jeremy Corbett ended the programme, which was usually finished by 
tallying the points and announcing the winning team, Corbett announced "I haven't even added them up, don't know why you guys [the international team] bothered coming it was always going to be Team New Zealand [that won]" ("New Zealand vs The World" 7 Days 57:26). Despite lightly mocking sub-identities of nationality throughout the broadcast, this affirms that the comedians are really patriotic New Zealanders, who just like to "have a laugh'.

However, despite issues of control and commercialisation, national identity is not simply a method of imposing control over a population, an unfortunate sacrifice that must be made in order to preserve any public sphere. The audience is treated as if they have something in common, and can therefore react to and discuss the broadcast material as common culture (Anderson et al. 11). The fostering of common ground reinforces certain core values, which is valuable in binding together New Zealand's small and widely scattered population and combating a tendency for cultural cringe (Horrocks "Themes" 9; Bell 22). Nationalism is habitually conceived of as a innate solidarity between citizens, despite actual circumstances of inequality (Anderson 257). New Zealand is flooded by imported cultural texts and products, and so the strong signalling of identity in nationally produced television works towards the development of a distinctive cultural identity that allows cohesive public sphere engagement (Farnsworth 335; Ong 55).

In creating a strong sense of identity and place, individual's come to recognise themselves as citizens, and are more responsive to interpellations that encourage investment in civic issues (Dahlgren 427). In order for democratic systems to succeed individuals need to consider themselves invested citizens, and the recurrent signalling of national identity in nationally produced New Zealand television is able to demonstrate not only what constitutes this identity, but what is at stake (Dahlgren 429; Couldry et al. 6). National identity is thus highly compatible with public sphere objectives which require citizens to debate as equals; the use of the meta-identity does not eliminate equality, but brackets it, allowing effective discussion and critique between citizens (Fraser 494). This feeling of community creates a commitment to the continuance and betterment of the state, encouraging citizens to make sacrifices to ensure this (Anderson 257). Nationalism is the dominant contemporary method of organising political groupings, and mediated reinforcement of a shared national identity and culture has a large role in the construction of a national identity that creates the opportunity for national citizens to come together as a cohesive group of politically motivated citizens (Schirato et al. 57; Crofts 271; Bell 22). 
While national identity's largely uncritiqued character is somewhat problematic, this is important to the ability of the mediated public sphere to critique other areas, avoiding being too confronting for the audience to engage. Despite television's preference for recognisable images of identity, these images are able to evolve in response to criticism or their audience, as television is not a static medium (Bell 24). The use of these meta-identity's are as conflicted as the rest of the public sphere, but have the potential to increase empathy and solidarity between social groups (Thussu 24; Bell 22). The audience of programmes such as Campbell Live are interpellated into a familiar cultural field whose rules they are familiar with, and to which membership is framed very positively, and as such, the use of a nationally demarcated meta-identity invites the widest potential audience into a space of critical public sphere. 


\section{Chapter 7: Conclusion}

The discourses circulated by the mediated public sphere of New Zealand television were found to be highly conflicted. The analysis of Campbell Live, Shortland Street, and 7 Days found that each programme used methods particular to their own genre to enact a form of critique, and that each method was active in engaging with norms, questioning power relationships, and interpellating viewers into participating in public sphere debate. However, all three programmes were limited by commercial imperatives, and therefore could not be too critical, as large audiences are needed to keep advertisers happy. Each programme was also constrained by particular requirements of their genre, which limited their ability to fulfil the more demanding requirements of a public sphere space.

The results of this research show that New Zealand television is clearly able to fulfil some public sphere requirements: they disseminate information, and each programme offers understandable and relatable accounts of politically relevant events and social concerns. The combination of television's use of images and conversational discourses makes it an easily understandable medium, and viewers are attracted by its ability to both entertain and inform (Bignell 160; Zoonen 100; Gauntlett 2). The combination of entertainment and information gives each programme access to a large number of viewers to address, whether it is the typical news information of Campbell Live, the personal sphere discussion of Shortland Street, or the satirising of the news on 7 Days. This information was discussed by all three programmes in the anticipated method of 'working through' that is prevalent in television, presenting information and contesting explanations and solutions without offering a singular, final explanation (Ellis, in Briggs 7). The working through of issues uses conversational discourse to offer citizen's diverse solutions which they can then choose to take further.

Campbell Live works to fulfil public sphere requirements through information dissemination, providing a rational critique of power, and the interpellation of citizens to take up an active role in the public sphere. The promotion of attitudes of rationality and reasonableness, and the coverage of contemporary news, meant that Campbell Live resembled a more traditional form of public sphere, prioritising detached, critical thinking (Dahlgren 419; Weber 70). The programme focuses on the top 3 or 4 news stories, first giving more in-depth information on the story, and then subjecting the story to in-depth comment, analysis and consideration through interviews and viewer emails. Viewers are 
given the information necessary for them to participate in discussion, while simultaneously being exposed to the values and discourses of critical thinking (Foucault "10 March" 372; Schirato et al. 52; Allaun 12). The discourses of Campbell Live framed critique and the distrust of power as a reasonable position to take, thereby complicating the exercise of power (Hartley 1; Foucault "Two Lectures" 31).

Campbell Live's particular contribution to the public sphere was the recurrent prompting of audience members to think about issues, form opinions and email the show, along with the inclusion of this email feedback into the programme's broadcast. The inclusion of multiple sections of these 'Your Opinion' sections in each broadcast lessened the impact of television's one-way relation to viewers, allowing the mass mediated public sphere to actually include citizen contributions (Thussu 24; Corner and Pels 3). Because these emails included citizens, who cannot usually access the public sphere offered by television, homogenisation of discourses and values was reduced (Anderson et al. xix). In this encouragement of active audience participation through email, viewers are interpellated into taking on the characteristics of active critique that Campbell Live promotes, promoting the open expression of opinion and dissent by facilitating such expression in the televised public sphere (Anderson et al. 9; Foucault "Space, Power" 165).

Shortland Street fulfilled the public sphere's requirement for information dissemination, democratic and inclusive methods of speech, and discussion that represents a wide range of topics and arguments. The programme used its large cast to represent a diversity of characters and viewpoints, and framed this emotional discussion in a domestic setting, due to its background as a genre that was designed for housewives (Bowles 188). Shortland Street used this structure to work through current social concerns, subjecting them to debate across its large cast that stretched throughout the long form narrative. The domestic setting representation of a diversity of opinions creates the potential for viewers to identify with the issues that Shortland Street represents, and therefore engage emotionally with them (Briggs 7; McCarthy "Studying" 47). These debates are never resolved due to soap's lack of narrative closure, and therefore the audience is not offered a solution by Shortland Street; rather, many potential courses of action and viewpoints are presented (Casey et al. 226; Mumford 18). This working through prompts audience discussion and opinion formation that is crucial for other forms of resistance and political engagement (Dahlgren 420).

In prioritising feminine discourses and the personal sphere Shortland Street creates a alternative space of public sphere engagement, in contrast to the typically rational public sphere of Campbell Live (Dahlgren 425). Issues of social inequality and conflict are made 
manageable and relatable by putting them into the settings and discourses of daily life (Silverstone 52). The accessible narrative of Shortland Street naturalises these alternate methods of public sphere engagement, authorising discourses of the personal and feminine for public use (Brown 8). This widens the public sphere to include a more diverse range of citizens and discussion than those who can engage if rational discourse is overly prioritised (Brown 8; Fraser 494). Emotional discourses require less education and literacy for viewers to understand, as they are similar to daily speech processes (Briggs 8; Anderson et al. 6). Shortland Street's departure from rational modes of discussion therefore could be said to aid in the democratising of the public sphere (Couldry et al. 33).

7 Days was the site of the most aggressive and continuous critique of power and its representatives. This was due in large part to genre, as comedy is committed to subverting expectations, thereby denaturalising norms that seek to work as unquestioned assumptions (Neale and Krutnik 83; J. Palmer 180; Foucault "Two Lectures" 44). The surprise of the comedic punch line means that subversion is to some extent inherent to comedy, and can encourage audience members to actively resist the exercise of power by problematising assumptions that are usually taken for granted (Murdock 179; Horrocks "Themes" 17). The subversive critique of comedy is attractive and engaging because of its entertainment value, and this entertainment leads audience members to pay more attention to the genre and potentially take up the discourse for their own use (Murdock 178). Comedy thus has the potential to become part of the audience's lived history, its values of critique and subversion becoming incorporated into a subject's habitus (Brown 13; Foucault "Space, Power" 165).

7 Days was particularly valuable to New Zealand's public sphere because of the comic's ability to speak the unspeakable, even on a system of mass broadcast such as television (J. Palmer 12). The comedians on 7 Days discussed news events and power figures, with this discussion often parodying powerful figures in a satiric manner, using exaggerated mimicry of their bodily movements in order to produce satire (Neale and Krutnik 20; Kercher 1; Brown 136). These comedic excesses draw upon discourses that are considered taboo, in order to deploy satiric critique in an aggressive manner (Neale and Krutnik 19; Murdock 177). These excesses of comic discourse not only oppose common assumptions of what can be said in public discussion, but work against discourses that seek to control individual's by denying the organic body and mute candid discussion (Bourdieu "Symbolic Power" 488; Foucault "Incitement" 491).

Despite these considerable strengths, the public sphere role that 7 Days, Shortland Street, and Campbell Live were able to take up was limited by the domination of commercial 
influences. The commercial pressures, combined with the genre requirements that each programme faced, produce a different limiting effect in each case. Campbell Live's rational critique was limited by the inclusion of soft news pieces that aimed to attract larger audiences; Shortland Street's emotional address led to social issues initially being addressed, but also sensationalised; and the critical and interrogatory disposition of comedy was likely to be vitiated, at least to some extent, because audience members were unlikely to take the comic stance of 7 Days seriously. These elements limited the critical potential of the programmes rather than eliminating it, producing ambiguous and conflicted sites which served both power and resistance. Yet despite commercial imperatives disposing the programmes to include elements that were simplified or sensational, these elements ensured a large audience was invested in the programmes (Crofts 269; Webb et al. 193; Schirato and Webb 174). This is important for a valid public sphere, as all citizens need a space that undertakes representation and discussion of relevant issues, and commercial imperatives push programmes to attract the widest range of audience members possible (Holland 220; Anderson et al. 6; Simons 181). When the programmes then took on a critical or informative role, they had the attention of a large and invested audience.

This conflict aptly demonstrates how power and resistance each constantly work to reclaim the other. The three programmes worked to circulate diverse discourses and subject positions that often conflicted with one another. The viewers were therefore offered a wide range of discourses, values, and meanings (Foucault "Two Lectures" 36; Foucault "Subject and Power" 342). The programmes increase the range of information and subject positions available to viewers, rather than telling subjects how to resist or accept the exercise of power (Foucault "Subject and Power" 342; Nealon 97). The public sphere offered by television is thus more active than is often assumed, with subjects offered a conflicting and ambiguous site of interpellations. The diversity of television's public sphere demonstrates that despite the ambiguous and shifting nature of power relations, power and resistance never occur as separate events. The exercise of power is always accompanied by the practice of resistance, just as resistance is always in response to power, and the balance of this relationship is constantly in flux and never final (Foucault "Critical Theory" 128; Foucault "Sex, Power" 167; Gauntlett 128). The programmes became the site of this conflict between power and resistance, and audience members could take part in the conflict by responding to some interpellations and refusing others.

While this research was designed to generate results that are relevant to the televised public sphere in entirety, it was somewhat limited by the time available for research and 
analysis, and would benefit from a wider study. While an attempt was made to ensure breadth by spreading analysis over three distinct genres, further research could be directed to the confirmation or denial of similarly conflicted public spheres in other programmes on New Zealand television, and similarities and differences between the public sphere of New Zealand and similar international spaces. 


\section{Works Cited}

"16 March." Campbell Live. TV3, New Zealand. 16 Mar. 2010. Television.

"17 March." Campbell Live. TV3, New Zealand. 17 Mar. 2010. Television.

"22 March." Campbell Live. TV3, New Zealand. 22 Mar. 2010. Television.

"23 March." Campbell Live. TV3, New Zealand. 23 Mar. 2010. Television.

"6 April." Campbell Live. TV3, New Zealand. 6 Apr. 2010. Television.

Alasuutari, Pertti. "Introduction: Three Phases of Reception Studies." Rethinking the Media Audience: The New Agenda. Ed. Pertti Alasuutari. London; Thousand Oaks, Calif.: Sage Publications, 1999. 1-21.

Allaun, Frank. Spreading the News: A Guide to Media Reform. Nottingham, England: Spokesman for the Campaign for Press and Broadcasting Freedom, 1988.

Althusser, Louis. "Ideology and Ideological State Apparatuses (Notes Towards an Investigation)." The Anthropology of the State: A Reader. Eds. Aradhana Sharma and Akhil Gupta. Malden, MA; Oxford: Blackwell Publishing, 2006. 86-111.

Anderson, Benedict. "Imagined Communities: Nationalism's Cultural Roots." The Cultural Studies Reader. Ed. Simon During. London: Routledge, 2007. 253-63.

Anderson, Rob, Robert Dardenne, and George M. Killenberg. The Conversation of Journalism: Communication, Community, and News. Westport, Conn.: Praeger, 1994.

Beauvoir, Simon de. "The Independent Woman." The Cultural Studies Reader. Ed. Simon During. London: Routledge, 2007. 337-57.

Bell, Claudia. "All We Need to Know Because Tv Tells Us So." $\underline{\text { New Zealand Television: A }}$

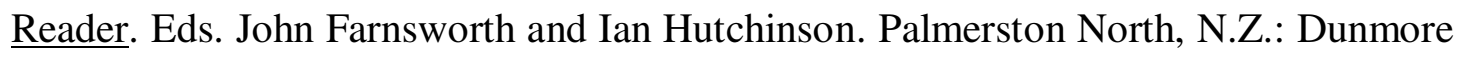
Press, 2001. 21-30.

Berger, Arthur Asa. 50 Ways to Understand Communication: A Guided Tour of Key Ideas and Theorists in Communication, Media, and Culture. Lanham: Rowman \& Littlefield Publishers, 2006.

Bignell, Jonathon. Media Semiotics: An Introduction. Second Edition. Manchester; New York: Palgrave, 2002.

Bouchard, Donald F. "Language, Counter-Memory, Practice : Selected Essays and Interviews." Trans. Donald F. Bouchard and Sherry Simon. Language, CounterMemory, Practice : Selected Essays and Interviews. Ed. Donald F. Bouchard. Ithaca, N.Y.: Cornell University Press, 1977. 15-25. 
Bourdieu, Pierre. "Field of Power, Literary Field and Habitus." The Cultural Studies Reader. Ed. Simon During. London: Routledge, 2007. 88-98.

Bourdieu, Pierre. "Language and Symbolic Power." The Discourse Reader. Eds. Adam Jaworski and Nikolas Coupland. London: Routledge, 2006. 480-90.

Bourdieu, Pierre. On Television. New York: New Press, 1998.

Bowles, Kate. "Soap Opera: 'No End of Story, Ever'." The Australian Tv Book. Ed. Graeme Turner and Stuart Cunningham. St. Leonards, N.S.W.: Allen \& Unwin, 2000. 117-29. Brady, Anita, and Tony Schirato. Understanding Judith Butler. London: Sage, 2011.

Briggs, Matt. Television, Audiences \& Everyday Life. Berkshire: Open University Press, 2010.

Brown, Mary Ellen. Soap Opera and Women's Talk: The Pleasure of Resistance. Thousand Oaks: Sage Publications, 1994.

Butler, Judith. "Burning Acts, Injurious Speech." The Discourse Reader. Eds. Adam Jaworski and Nikolas Coupland. London: Routledge, 2006. 499-505.

Campbell, Richard. "Securing the Middle Ground: Reporter Formulas in 60 Minutes." Television: The Critical View. Ed. Horace Newcomb. New York: Oxford University Press, 1994. 303 - 31.

Casey, Bernadette, et al. Television Studies: The Key Concepts. London; New York: Routledge, 2002.

Corner, John, and Dick Pels. "Introduction: The Re-Styling of Politics." Media and the Restyling of Politics: Consumerism, Celebrity and Cynicism. Eds. John Corner and Dick Pels. London: SAGE, 2003. 1-18.

Couldry, Nick, Sonia Livingstone, and Tim Markham. Media Consumption and Public Engagement : Beyond the Presumption of Attention. Basingstoke, Hampshire; New York: Palgrave Macmillan, 2007.

Crofts, Stephen. "Television News." Television in New Zealand: Programming the Nation. Eds. Roger Horrocks and Nick Perry. Auckland [N.Z.]: Oxford University Press, 2004. $255-71$.

Dahlgren, Peter. "Television, Public Spheres and Civic Cultures." A Companion to Television. Ed. Janet Wasko. Malden, MA: Blackwell Publishing Ltd, 2005 411-32.

Danaher, G. Foucault: A Critical Introduction. Sydney: Allen \& Unwin, 2011.

Davies, Christie. The Mirth of Nations. New Brunswick, NJ: Transaction Publishers, 2002.

Dreyfus, Hubert L., and Paul Rabinow. Michel Foucault: Beyond Structuralism and Hermeneutics. Brighton: Harvester, 1982. 
Dunleavy, Trisha. "Shortland Street's Elusive 'Haven': The Unstable Community as Metaphor in the Prime-Time Soap." New Zealand Television: A Reader. Eds. John Farnsworth and Ian Hutchinson. Palmerston North, N.Z.: Dunmore Press, 2001. 41-49.

Elliott, Matt. Kiwi Jokers: The Rise and Rise of New Zealand Comedy. Auckland [N.Z.]: Harper Collins Publishers N.Z., 1997.

"Episode 2." 7 Days. TV3, New Zealand. 14 May 2010. Television.

"Episode 6." 7 Days. TV3, New Zealand. 11 Jun. 2010. Television.

Escobar, Arturo. "Identity." A Companion to the Anthropology of Politics. Eds. David Nugent and Joan Vincent. Malden, MA: Blackwell Publishing, 2004. 248-66.

Farnsworth, John. "Local and Global Contexts of New Zealand Television." New Zealand Television: A Reader. Eds. John Farnsworth and Ian Hutchinson. Palmerston North, N.Z.: Dunmore Press, 2001. 332-42.

Fiske, John. Television Culture. London; New York: Methuen, 1987.

Foucault, Michel. "3 March 1982: Second Hour." Trans. Graham Burchell. The Hermeneutics of the Subject: Lectures at the CollèGe De France, 1981-1982. Ed. Frédéric Gros. New York: Palgrave-Macmillan, 2005. 355-70.

Foucault, Michel. "5 January 1983: Second Hour." Trans. Graham Burchell. The Government of Self and Others. Ed. Frédéric Gros. Basingstoke: Palgrave Macmillan, 2010. 25-40.

Foucault, Michel. "10 February 1982: Second Hour." Trans. Graham Burchell. The Hermeneutics of the Subject: Lectures at the CollèGe De France, 1981-1982. Ed. Frédéric Gros. New York: Palgrave-Macmillan, 2005. 229-46.

Foucault, Michel. "10 March 1982: First Hour." Trans. Graham Burchell. The Hermeneutics of the Subject: Lectures at the CollèGe De France, 1981-1982. Ed. Frédéric Gros. New York: Palgrave-Macmillan, 2005. 371-94.

Foucault, Michel. "12 January 1983: First Hour." Trans. Graham Burchell. The Government of Self and Others. Ed. Frédéric Gros. Basingstoke: Palgrave Macmillan, 2010. 41-59.

Foucault, Michel. "17 March 1982: First Hour." Trans. Graham Burchell. The Hermeneutics of the Subject: Lectures at the CollèGe De France, 1981-1982. Ed. Frédéric Gros. New York: Palgrave-Macmillan, 2005. 413-36.

Foucault, Michel. "27 January 1982: Second Hour." Trans. Graham Burchell. The Hermeneutics of the Subject: Lectures at the CollèGe De France, 1981-1982. Ed. Frédéric Gros. New York: Palgrave-Macmillan, 2005. 149-67. 
Foucault, Michel. "Critical Theory/Intellectual History." Critique and Power: Recasting the Foucault/Habermas Debate. Ed. Michael Kelly. Cambridge, Mass.: MIT Press, 1994. 109-37.

Foucault, Michel. Discipline and Punish: The Birth of the Prison. Trans. Alan Sheridan. New York: Vintage Books, 1995.

Foucault, Michel. "Governmentality." The Anthropology of the State: A Reader. Eds. Aradhana Sharma and Akhil Gupta. Malden, MA; Oxford: Blackwell Publishing, 2006. 131-43.

Foucault, Michel. The History of Sexuality: Volume 1: An Introduction. Trans. Robert Hurley. New York: Vintage Books, 1980.

Foucault, Michel. "The Incitement to Discourse." The Discourse Reader. Eds. Adam Jaworski and Nikolas Coupland. London: Routledge, 2006. 491-98.

Foucault, Michel. "Intellectuals and Power." Trans. Donald F. Bouchard and Sherry Simon. Language, Counter-Memory, Practice: Selected Essays and Interviews. Ed. Donald F. Bouchard. Ithaca, N.Y.: Cornell University Press, 1977. 205-17.

Foucault, Michel. "Interview with Michel Foucault." Trans. Robert Hurley and others. Power. Ed. James D. Faubion. New York: New Press, 2000. 239-97.

Foucault, Michel. "On Power." Trans. Alan Sheridan and others. Politics, Philosophy, Culture: Interviews and Other Writings, 1977-1984. Ed. Lawrence D. Kritzman. New York: Routledge, 1988. 96-109.

Foucault, Michel. "Sex, Power, and the Politics of Identity." Trans. Robert Hurley and others. Ethics: Subjectivity and Truth. Ed. Paul Rabinow. New York: New Press, 1997. 16373.

Foucault, Michel. "Space, Power and Knowledge." The Cultural Studies Reader. Ed. Simon During. London: Routledge, 2007. 164-71.

Foucault, Michel. "The Subject and Power." Trans. Robert Hurley and others. Power. Ed. James D. Faubion. New York: New Press, 2000. 326-48.

Foucault, Michel. "Technologies of the Self." Trans. Robert Hurley and others. Ethics: Subjectivity and Truth. Ed. Paul Rabinow. New York: New Press, 1997. 223-51.

Foucault, Michel. "Two Lectures." Critique and Power : Recasting the Foucault/Habermas Debate. Ed. Michael Kelly. Cambridge, Mass.: MIT Press, 1994. 17-46.

Fraser, Nancy. "Rethinking the Public Sphere: A Contribution to the Critique of Actually Existing Democracy." The Cultural Studies Reader. Ed. Simon During. London: Routledge, 2007. 488-506. 
Gauntlett, David. Media, Gender and Identity: An Introduction. London; New York: Routledge, 2008.

Geraghty, Christine. "The Study of Soap Opera." A Companion to Television. Ed. Janet Wasko. Malden, MA: Blackwell Publishing Ltd, 2005. 308-23.

Geraghty, Christine. Women and Soap Opera: A Study of Prime Time Soaps. Cambridge, UK: Polity Press, 1991.

Gilbert, Joanne R. Performing Marginality: Humor, Gender, and Cultural Critique. Detroit: Wayne State University Press, 2004.

Gordon, Colin. "Introduction." Trans. Robert Hurley and others. Power. Ed. James D. Faubion. New York: New Press, 2000. xi-xli.

Gramsci, Antonio. "State and Civil Society." The Anthropology of the State: A Reader. Eds. Aradhana Sharma and Akhil Gupta. Malden, MA; Oxford: Blackwell Publishing, 2006. 71-85.

Gupta, Akhil. "Blurred Boundaries: The Discourse of Corruption, the Culture of Politics, and the Imagined State." The Anthropology of the State: A Reader. Eds. Aradhana Sharma and Akhil Gupta. Malden, MA; Oxford Blackwell Publishing, 2006. 211-42.

Gupta, Akhil. "Imagining Nations." A Companion to the Anthropology of Politics. Eds. David Nugent and Joan Vincent. Malden, MA: Blackwell Publishing, 2004. 267-81.

Hall, Stuart. "Popular Culture and the State." The Anthropology of the State: A Reader. Eds. Aradhana Sharma and Akhil Gupta. Malden, MA; Oxford: Blackwell Publishing, 2006. 360-80.

Hartley, John. Understanding News. London; New York: Methuen, 1982.

Hobson, Dorothy. Soap Opera. Cambridge, UK; Malden, MA: Polity, 2003.

Holland, Patricia. The Angry Buzz: This Week and Current Affairs Television. London: I.B. Tauris, 2006.

Hopkins, Alison Julie. "Convenient Fictions: The Script of Lesbian Desire in the Post-Ellen Era: A New Zealand Perspective." Victoria University of Wellington, 2009.

Horrocks, Roger. "Construction Site: Local Content on Television." Television in New Zealand: Programming the Nation. Eds. Roger Horrocks and Nick Perry. Auckland [N.Z.]: Oxford University Press, 2004. 272-85.

Horrocks, Roger. "The History of New Zealand Television: 'an Expensive Medium for a Small Country'." Television in New Zealand: Programming the Nation. Eds. Roger Horrocks and Nick Perry. Auckland [N.Z.]: Oxford University Press, 2004. 20-43. 
Horrocks, Roger. "Studying New Zealand Television: Themes, Methods, Perspectives." Television in New Zealand: Programming the Nation. Eds. Roger Horrocks and Nick Perry. Auckland [N.Z.]: Oxford University Press, 2004.

Kelly, Michael. "Introduction." Critique and Power: Recasting the Foucault/Habermas Debate. Ed. Michael Kelly. Cambridge, Mass.: MIT Press, 1994. 1-13.

Kercher, Stephen E. Revel with a Cause: Liberal Satire in Postwar America. Chicago: University of Chicago Press, 2006.

Lealand, Geoff. "The Problem of Quality Television: Television Schedules, Audience Demographics and Cultural Policy in New Zealand." Quality Tv: Contemporary American Television and Beyond. Eds. Janet McCabe and Kim Akass. London; New York: I.B. Tauris, 2007. 129-42.

Lealand, Geoff. "Regulation - What Regulation? Cultural Diversity and Local Content in New Zealand Television." New Zealand Television: A Reader. Eds. John Farnsworth and Ian Hutchinson. Palmerston North, N.Z.: Dunmore Press, 2001. 211-24.

Lewis, Paul. Cracking Up: American Humor in a Time of Conflict. Chicago: University of Chicago Press, 2006.

Mattelart, Armand, and Michele Mattelart. Rethinking Media Theory: Signposts and New Directions. Minneapolis: University of Minnesota Press, 1992.

McCarthy, Anna. "Realism and Soap Opera." The Television Genre Book. Ed. Glen Creeber. London: British Film Institute, 2001. 49-54.

McCarthy, Anna. "Studying Soap Opera." The Television Genre Book. Ed. Glen Creeber. London: British Film Institute, 2001. 47-49.

McHoul, Alec, and Wendy Grace. A Foucault Primer: Discourse, Power and the Subject. Carlton, Vic.: Melbourne University Press, 1993.

Mumford, Laura Stempel. Love and Ideology in the Afternoon : Soap Opera, Women, and Television Genre. Bloomington: Indiana University Press, 1995.

Murdock, Graham. "Public Broadcasting and Democratic Culture: Consumers, Citizens, and Communards." A Companion to Television. Ed. Janet Wasko. Malden, MA: Blackwell Publishing Ltd, 2005. 174-98.

Neale, Steve. "Studying Genre." The Television Genre Book. Ed. Glen Creeber. London: British Film Institute, 2001. 1-3.

Neale, Steve, and Frank Krutnik. Popular Film and Television Comedy. London; New York: Routledge, 1990. 
Nealon, Jeffrey T. Foucault Beyond Foucault: Power and Its Intensifications since 1984. Stanford, California: Stanford University Press, 2008.

Neuwirth, Allan. They'll Never Put That on the Air: An Oral History of Taboo-Breaking Tv Comedy. New York: Allworth Press, 2006.

"The New Zealand vs. The World Special." 7 Days. TV3, New Zealand. 7 May 2010. Television.

Nugent, David. "Governing States." A Companion to the Anthropology of Politics. Eds. David Nugent and Joan Vincent. Malden, MA: Blackwell Publishing, 2004. 198-215.

Ong, Aihwa. "Citizenship." A Companion to the Anthropology of Politics. Eds. David Nugent and Joan Vincent. Malden, MA: Blackwell Publishing, 2004. 55-68.

Palmer, Gareth. Discipline and Liberty: Television and Governance. Manchester, UK; New York: Manchester University Press; New York, 2003.

Palmer, Jerry. The Logic of the Absurd: On Film and Television Comedy. London: BFI, 1987. Perry, Nick. The Dominion of Signs: Television, Advertising, and Other New Zealand Fictions. Auckland, N.Z.: Auckland University Press, 1994.

Ransom, John S. Foucault's Discipline: The Politics of Subjectivity. Durham: Duke University Press, 1997.

Reeves, Jimmie L., Mark C. Rogers, and Michael M. Epstein. "Quality Control: The Daily Show, the Peabody and Brand Discipline." Quality Tv: Contemporary American Television and Beyond. Eds. Janet McCabe and Kim Akass. London; New York: I.B. Tauris, 2007. 79-97.

Rose, Nikolas. "Governing "Advanced" Liberal Democracies." The Anthropology of the State: A Reader. Eds. Aradhana Sharma and Akhil Gupta. Malden, MA; Oxford: Blackwell Publishing, 2006. 144-62.

Schirato, Tony, et al. Understanding Media Studies. South Melbourne: Oxford University Press, 2010.

Schirato, Tony, and Jen Webb. Understanding the Visual. London: Sage, 2004.

Seiter, Ellen, and Mary Jeanne Wilson. "Soap Opera Survival Tactics." Thinking Outside the Box: A Contemporary Television Genre Reader. Eds. Gary R. Edgerton and Brian Rose. Lexington: University Press of Kentucky, 2005. 136-55.

Sheridan, Alan. Michel Foucault: The Will to Truth. London; New York: Tavistock, 1980.

Shershow, Scott Cutler. Laughing Matters : The Paradox of Comedy. Amherst, MA: University of Massachusetts Press, 1986.

Silverstone, Roger. Television and Everyday Life. London; New York: Routledge, 1994. 
Simons, Jon. "Popular Culture and Mediated Politics: Intellectuals, Elites and Democracy. ." Media and the Restyling of Politics: Consumerism, Celebrity and Cynicism. Eds. John Corner and Dick Pels. London: SAGE, 2003. 171-89.

Slade, Christina. The Real Thing : Doing Philosophy with Media. New York: Peter Lang, 2002.

Smart, Barry. Michel Foucault. Chichester, U.K.; E. Horwood; London: Tavistock, 1985.

Thussu, Daya Kishan. News as Entertainment: The Rise of Global Infotainment. Thousand Oaks, Calif.: Sage, 2007.

Tulloch, John. "The Implied Audience in Soap Opera Production: Everyday Rhetorical Strategies among Television Professionals." Rethinking the Media Audience : The New Agenda. Ed. Pertti Alasuutari. London; Thousand Oaks, Calif.: Sage Publications, 1999. 151-78.

Turner, Graeme. Ordinary People and the Media: The Demotic Turn. London: SAGE, 2009.

Turner, Graeme. "Studying Television." The Australian Tv Book. Eds. Graeme Turner and Stuart Cunningham. St. Leonards, N.S.W.: Allen \& Unwin, 2000. 3-12.

Turner, Stephen. "Representing the Country: Adidas Aotearoa." Television in New Zealand: Programming the Nation. Eds. Roger Horrocks and Nick Perry. Auckland [N.Z.]: Oxford University Press, 2004. 91-110.

Webb, Jen, Tony Schirato, and Geoff Danaher. Understanding Bourdieu. Crows Nest, N.S.W.: Allen \& Unwin, 2002.

Weber, Max. "Bureaucracy." The Anthropology of the State: A Reader. Eds. Aradhana Sharma and Akhil Gupta. Malden, MA; Oxford: Blackwell Publishing, 2006. 49-70.

Zoonen, Liesbet van. "'after Dallas and Dynasty We Have... Democracy': Articulating Soap, Politics and Gender." Media and the Restyling of Politics: Consumerism, Celebrity and Cynicism. Eds. John Corner and Dick Pels. London: SAGE, 2003. 99-116. 